\title{
Loss-of-Huntingtin in Medial and Lateral Ganglionic Lineages Differentially Disrupts Regional Interneuron and Projection Neuron Subtypes and Promotes Huntington's Disease-Associated Behavioral, Cellular, and Pathological Hallmarks
}

\author{
Mark F. Mehler, ${ }^{1,2,3,4,5,6,7,8,9,10}$ @Jenna R. Petronglo, ${ }^{1,2,3,6}$ Eduardo E. Arteaga-Bracho, ${ }^{1,2,4,6}$ @Maria E. Gulinello, ${ }^{4,6}$ \\ Michael L. Winchester, ${ }^{1,2,3,6}$ Nandini Pichamoorthy, ${ }^{1,2,3,6}$ Stephen K. Young, ${ }^{1,2,3,6}$ Christopher D. DeJesus, ${ }^{1,2,4,6}$ \\ Hifza Ishtiaq, ${ }^{1,2}$ Solen Gokhan, ${ }^{1,2,3,6}$ and ${ }^{\circ}$ Aldrin E. Molero ${ }^{1,2,3,6}$ \\ ${ }^{1}$ Roslyn and Leslie Goldstein Laboratory for Stem Cell Biology and Regenerative Medicine, ${ }^{2}$ Institute for Brain Disorders and Neural Regeneration, ${ }^{3}$ The \\ Saul R. Korey Department of Neurology, ${ }^{4}$ Dominick P. Purpura Department of Neuroscience, ${ }^{5}$ Department of Psychiatry and Behavioral Sciences, ${ }^{6}$ Rose F. \\ Kennedy Center for Research on Intellectual and Developmental Disabilities, ${ }^{7}$ Einstein Cancer Center, ${ }^{8}$ Ruth L. and David S. Gottesman Institute for Stem \\ Cell Biology and Regenerative Medicine, ${ }^{9} \mathrm{Center}$ for Epigenomics, and ${ }^{10}$ Institute for Aging Research, Albert Einstein College of Medicine, Bronx, New York \\ 10461
}

Emerging studies are providing compelling evidence that the pathogenesis of Huntington's disease (HD), a neurodegenerative disorder with frequent midlife onset, encompasses developmental components. Moreover, our previous studies using a hypomorphic model targeting huntingtin during the neurodevelopmental period indicated that loss-of-function mechanisms account for this pathogenic developmental component (Arteaga-Bracho et al., 2016). In the present study, we specifically ascertained the roles of subpallial lineage species in eliciting the previously observed HD-like phenotypes. Accordingly, we used the Cre-loxP system to conditionally ablate the murine huntingtin gene $\left(\mathrm{Htt}^{\mathrm{flx}}\right)$ in cells expressing the subpallial patterning markers Gsx2 (Gsx2-Cre) or Nkx2.1 (Nkx2.1-Cre) in $\mathrm{Htt}{ }^{\mathrm{flx}}$ mice of both sexes. These genetic manipulations elicited anxiety-like behaviors, hyperkinetic locomotion, age-dependent motor deficits, and weight loss in both $\mathrm{Htt}^{\mathrm{flx}}$;Gsx2-Cre and $\mathrm{Htt}^{\mathrm{flx}}$;Nkx2.1-Cre mice. In addition, these strains displayed unique but complementary spatial patterns of basal ganglia degeneration that are strikingly reminiscent of those seen in human cases of HD. Furthermore, we observed early deficits of somatostatin-positive and Reelin-positive interneurons in both Htt subpallial null strains, as well as early increases of cholinergic interneurons, Foxp ${ }^{+}$arkypallidal neurons, and incipient deficits with age-dependent loss of parvalbuminpositive neurons in $\mathrm{Htt}^{\mathrm{flx}} ; \mathrm{Nkx}$ 2.1-Cre mice. Overall, our findings indicate that selective loss-of-huntingtin function in subpallial lineages differentially disrupts the number, complement, and survival of forebrain interneurons and globus pallidus GABAergic neurons, thereby leading to the development of key neurological hallmarks of HD during adult life. Our findings have important implications for the establishment and deployment of neural circuitries and the integrity of network reserve in health and disease.

Key words: cell vulnerability; development; interneurons; neurodegeneration; pathogenesis; subpallium

\section{Significance Statement}

Huntington's disease (HD) is a progressive degenerative disorder caused by aberrant trinucleotide expansion in the huntingtin gene. Mechanistically, this mutation involves both loss- and gain-of-function mechanisms affecting a broad array of cellular and molecular processes. Although huntingtin is widely expressed during adult life, the mutant protein only causes the demise of selective neuronal subtypes. The mechanisms accounting for this differential vulnerability remain elusive. In this study, we have demonstrated that loss-of-huntingtin function in subpallial lineages not only differentially disrupts distinct interneuron species early in life, but also leads to a pattern of neurological deficits that are reminiscent of HD. This work suggests that early disruption of selective neuronal subtypes may account for the profiles of enhanced regional cellular vulnerability to death in HD. 


\section{Introduction}

Huntington's disease (HD), a relentlessly progressive neurodegenerative disorder, is caused by aberrant expansion of a polyglutamine tract in the pan-neural protein Huntingtin (Htt). Htt is a pleiotropic protein that encompasses a wide spectrum of seminal cellular roles during both the embryonic and postdevelopmental periods (Cattaneo et al., 2005; Marques Sousa and Humbert, 2013). We and others have demonstrated a compendium of neural developmental abnormalities associated with mutant Htt ranging from defects in neuroectodermal specification (Nguyen et al., 2013a; Conforti et al., 2018), abnormalities in neurogenesis within pallial and subpallial neuronal subtypes (Nguyen et al., 2013b; Molina-Calavita et al., 2014; Siebzehnrübl et al., 2018), changes in the timing of striatal medium spiny neuron (MSN) specification and migration within striatal germinative zones, and neuronal differentiation as well as maturational abnormalities of the chemo-architecture of the striatum (Molero et al., 2009; HD iPSC Consortium, 2017). Using an inducible Cre ${ }^{\text {ERT2 }}$ system to drive the excisional recombination of mutant Htt in a temporally defined manner, we demonstrated that restricted expression of this pathogenic protein during development elicits the key hallmarks of HD during later life (Molero et al., 2016). These findings strongly suggest that HD-associated developmental impairments play a key pathogenic role in disease onset.

Interestingly, both the loss of wild-type Htt and the presence of mutant Htt similarly deregulate a common repertoire of developmental processes, suggesting that loss-of-function mechanisms underlie these alterations (Nguyen et al., 2013a,b; Kerschbamer and Biagioli, 2015). In a previous study, we interrogated the role of loss-of-function mechanisms in HD pathogenesis by using a mouse model expressing very low levels of wild-type Htt until postnatal day 21 (Arteaga-Bracho et al., 2016). These mice developed a plethora of HD hallmarks in adult life, including neurological and skeletal muscle alterations, striatal and cortical degeneration, and white matter tract impairments, with the latter being well recognized as a developmental biomarker of HD (Gómez-Tortosa et al., 2001; Beglinger et al., 2005; Rosas et al., 2006; Bohanna et al., 2011; Phillips et al., 2014). The neurological parallels between models with time-selective loss of wild-type Htt function and time-selective expression of mutant huntingtin lend credence to the case that developmental impairments associated with loss-of-function developmental mechanisms play a key role in HD pathogenesis. Because the genetic manipulation we undertook to regulate wild-type $\mathrm{Htt}$ expression in a timely manner was common to all cells, we were unable to define whether pathogenic $\mathrm{Htt}$-associated developmental disruptions were due to involvement of a specific cellular lineage(s).

This report describes experiments designed to determine whether the loss-of-Htt function in discrete subpallial lineages

Received Sept. 21, 2018; revised Dec. 21, 2018; accepted Dec. 29, 2018.

Author contributions:M.F.M., J.R.P., E.E.A.-B., M.E.G., M.L.W., N.P., C.D.D., H.I., S.G., and A.E.M. edited the paper; A.E.M. wrote the first draft of the paper. M.F.M.,S.G., and A.E.M. designed research; J.R.P., E.E.A.-B., M.E.G., M.L.W., N.P., S.K.Y., C.D.D., H.I., and A.E.M. performed research; S.G. and A.E.M. contributed unpublished reagents/analytic tools; M.F.M., J.R.P., E.E.A.-B., M.E.G., S.K.Y., and A.E.M. analyzed data; M.F.M., J.R.P., and A.E.M. wrote the paper.

This work was supported by the National Institutes of Health (National Institute of Neurological Disorders and Stroke Grant R01NS073758 to A.E.M.; Grants R01NS071571 and R01NS096144 to M.F.M.; and Eunice Kennedy Shriver National Institute of (hild Health and Human Development Grant HD071593) and by the F.M. Kirby, Alpern Family, Harold and Isabel Feld, and Roslyn and Leslie Goldstein foundations (M.F.M.).

The authors declare no competing financial interests.

Correspondence should be addressed to Aldrin E. Molero at aldrin.molero@einstein.yu.edu.

https://doi.org/10.1523/JNEUROSCI.2443-18.2018

Copyright $@ 2019$ the authors $\quad$ 0270-6474/19/391893-18\$15.00/0 recapitulates $\mathrm{HD}$-like phenotypes. To accomplish this goal, we used the Cre-loxP system to conditionally ablate wild-type Htt in two distinctive subpallial lineages and their corresponding progeny: Gsx2 and Nkx2.1 lineages. The Gsx2 lineage gives rise to the most vulnerable cell-type in $\mathrm{HD}$, the striatal MSN, as well as to a complement of GABAergic somatostatin (SST), and calretinin (CR) interneurons and Foxp $2^{+}$arkypallidal neurons (Qin et al., 2016). Conversely, the Nkx2.1 lineage gives rise to forebrain parvalbumin (PV) GABAergic neurons, including the prototypical subtype occupying the globus pallidus (GP), another major neural structure targeted in $\mathrm{HD}$, as well as a complement of SST ${ }^{+}$ GABAergic interneurons, and cholinergic interneurons (Xu et al., 2008; Welagen and Anderson, 2011). Accordingly, by using a battery of behavioral and neuropathological tests, we examined the effects of Htt ablation within these subpallial interneuron lineages and associated roles in provoking the neurological hallmarks that characterize HD mouse models.

\section{Materials and Methods}

Animals

Chimeric mice carrying the floxed Htt allele were generated in house by blastocyst injections using the embryonic stem cell (ESC) clone EPD0635_1_E02 from the EuMMC repository (I.D. 40876, GenBank file https://www.i-dcc.org/imits/targ_rep/alleles/18237/escell-clone-genbankfile). These cells correspond to the JM8A1.N3 line C57BL/6. F1 offspring were generated by mating the knock-out first chimera with a wild-type C57BL mice. The F1 offspring were initially screened for positive mutants using primers targeting the neomycin construct (forward: $5^{\prime}$-CAA GATGGATTGCACGCAGG-3'; reverse 5'-TTCAGTGACAACGTCGA GCA-3') within the promoter-driven cassette (Fig. $1 A$ ). To verify the specificity of construct recombination within the Htt locus, we used a long-range PCR approach using specific primers flanking the most upstream sequence of the $5^{\prime}$-arm (forward: 5'-GAACTTCGGAATAG GAACTTCG-3'; reverse: 5'-ACCATTCACATTGGCAACAA-3') and the most downstream sequence of the $3^{\prime}$-arm (forward: $5^{\prime}$-GTCTG AGCTCGCCATCAGTT-3'; reverse: 5'-CTGACAGCAACCAGACAG GA-3'). Positive F1 mice were subsequently mated with mice expressing flippase (R26-FLPo; The Jackson Laboratory, catalog \#007844), which leads to the excision of the promoter-driven cassette (L1L2_BACT_P) flanked by the FRT sites but preserves the two loxP sequences flanking the exon 3 of $\mathrm{Htt}$. For the generation of the conditional knock-out mice used in this study, homozygous mice carrying the floxed exon $3 \mathrm{of} \mathrm{Htt}$, hereafter called $\mathrm{Htt}^{\mathrm{flx}}$, were subsequently mated with hemizygous mice expressing Cre recombinase from the promoters Gsx2-Cre (The Jackson Laboratory, catalog \#025856) and Nkx2.1-Cre (The Jackson Laboratory, catalog $\# 008661)$. As controls, we used $\mathrm{Htt}^{\mathrm{flx}}$ littermate mice lacking the corresponding Cre driver construct. Accordingly, our mating schema consisted of either $\mathrm{Htt}^{\mathrm{flx}} \times \mathrm{Htt}^{\mathrm{flx}}$; $\mathrm{Gsx} 2-\mathrm{Cre}$ or $\mathrm{Htt}^{\mathrm{flx}} \times \mathrm{Htt}^{\mathrm{flx}} ; \mathrm{Nkx} 2.1-\mathrm{Cre}$ mice. For fate-mapping experiments, our mutant mice also carried the fluorescence reporter gene, ZsGreen (C57BL/6 RCL-ZsGreen; The Jackson Laboratory, catalog \#007906). The Nkx2.1-Cre and Gsx2-Cre mice were $\mathrm{C} 57 \mathrm{BL} / 6$ and demonstrated to have similar weight profiles, behavioral performances, and histological features to those displayed by $\mathrm{Htt}^{\mathrm{flx}}$ control mice. The original strain of the R26-FLPo was 129S4/SvJaeSor, which, before its use in our studies, was outbred in house by backcrossing for $>10$ generations with C57BL/6 wild-type mice. For genotyping, we used standard PCR-based methods from genomic DNA isolated from tail samples. Accordingly, we use the following primers: (1) $\mathrm{Htt}^{\mathrm{flx}}: 5^{\prime}$ GGGCGGGCTTAGCTTGTTGGAT-3' (forward) and 5'-GTGGACT GTGGTGAGCAGCAT-3' (reverse); (2) Nkx2.1-Cre: 5' -CTCTGGTGG CTGCCTAAAAC-3' (forward) and 5'-CGGTTATTCAACTTGCA CCA-3' (reverse); (3) Gsx2-Cre: 5'-AGGTACAGGAGGTAGTCCC TC-3' (forward) and 5'-TTGGCGCGCCTGTGAAGCGTTGGACAGA GGCCC-3' (reverse); and ZsGreen: 5'-AACCAGAAGTGGCACCT GAC-3' (forward) and 5'-GGCATTAAAGCAGCGTATCC-3' (reverse). 
A

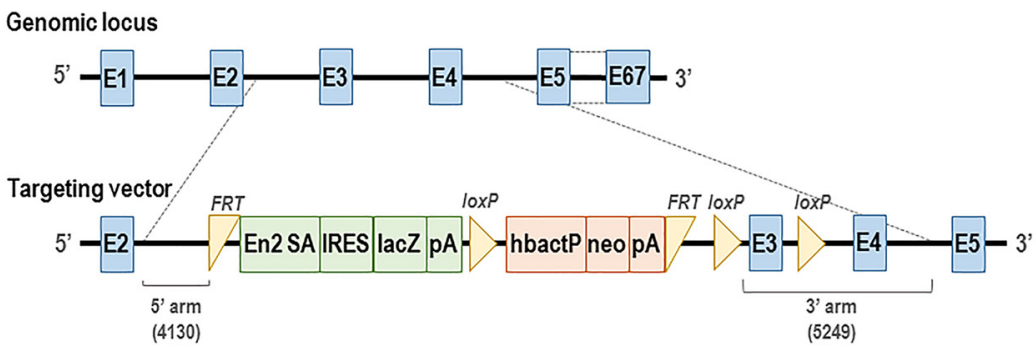

Targeted allele

Following FLPo recombination $F R T$ loxP loxP

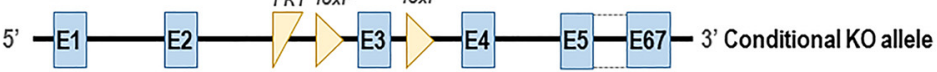

\section{Following Cre recombination}
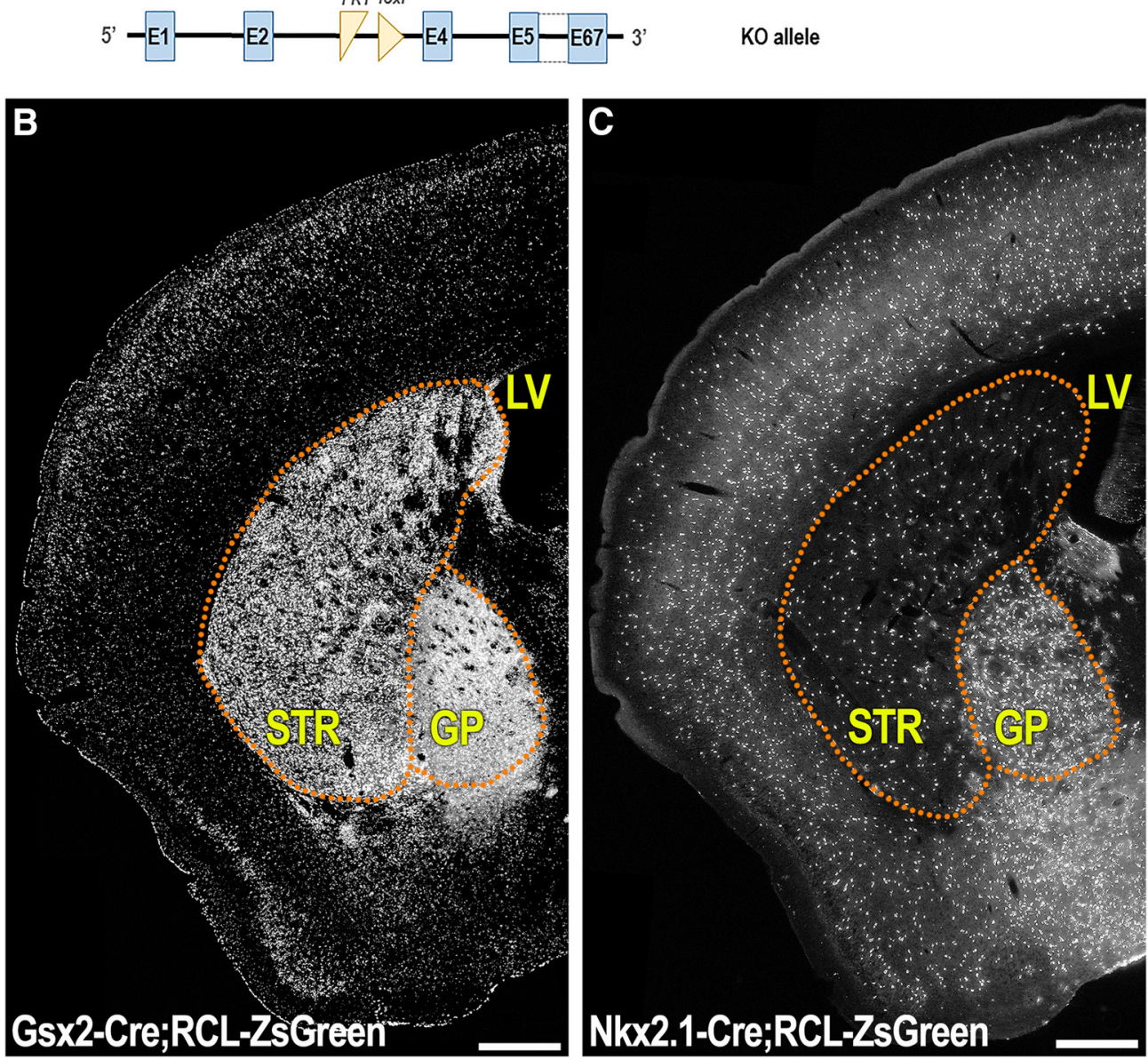

Figure 1. Schematic of the molecular strategy for the generation of a huntingtin-null mice and the corresponding spatial pattern of neural cells derived from the Gsx2 and Nkx2.1 lineages. $\boldsymbol{A}$, The endogenous huntingtin gene was targeted via homologous recombination generating ES(s with a huntingtin allele carrying a loxPfloxed exon 3 and a FRT floxed $\beta$-Gal)/Neo cassette within intron 2. We generated chimeric mice by blastocyst injection and, later, their corresponding progeny were screened with PCR to identify mice carrying the targeted allele. To remove the $\beta$-Gal/Neo cassette, these mice were crossed with a FLP0-deleter strain, thus generating mice carrying the conditional knock-out (KO) allele (Htt ${ }^{\text {flx }}$ ). Crossing this line with mice expressing Cre-recombinase produce the conditional huntingtin-null mice used in this study (K0 allele). $\boldsymbol{B}$ and $\boldsymbol{C}$ correspond to 1-month-old forebrain coronal sections showing Gsx2 (B) and Nkx2.1 ( $)$ lineages with the inducible fluorescent reporter ZsGreen. LV: Lateral Ventricle; STR: Striatum; GP: Globus Pallidum. Scale bars in $\boldsymbol{B}$ and $\boldsymbol{C}$ correspond to $500 \mu \mathrm{m}$.

All experimental procedures were performed according to the National Institutes of Health's Guidelines for the Care and Use of Laboratory Animals and were in accordance with protocol approval from the Institutional Animal Care and Use Committee of the Albert Einstein College of
Medicine (protocol \#21131207). Mice were housed in a temperaturecontrolled barrier facility with lighting kept on a fixed $12 \mathrm{~h}$ light and $12 \mathrm{~h}$ dark cycle and with access to water and food ad libitum. Each experimental mouse cohort used in our studies had a 1:1 male:female ratio. 


\section{Behavioral tests}

Motoric and neuropsychiatric tests were performed in both female and male mice longitudinally at 3,9 , and 12 months of age with the openfield, balance beam, rotarod, and dark-light box tests. All tests were performed after $1 \mathrm{~h}$ of acclimation in the testing room during the light cycle.

Open-field test. Mice were placed in an opaque opalescent acrylic (16 square inches) and allowed to freely explore the arena for $10 \mathrm{~min}$, during which time voluntary locomotion (total distance traveled in centimeters) and explorations were recorded and thereafter analyzed using Ethovision software (Noldus).

Balance beam test. Motor coordination deficits were measured as the number of slips made while traversing a rectangular wooden beam as described previously (Arteaga-Bracho et al., 2016). Before the test, all mice were pretrained on a wide plank $(3 \mathrm{~cm})$ to encourage reliable crossing. The start side was brightly illuminated and the end side had a small, darkened chamber to encourage the mice to cross. Immediately after pretraining, missteps (slips as defined by when the paw slipped below the midline of the beam) were assessed on a 1.5 -cm-diameter beam.

Rotarod test. Each mouse was placed on the rotarod with increasing speed, from 0 to $10 \mathrm{~cm} \mathrm{~s}^{-1}$ (increasing by $0.2 \mathrm{~cm} \mathrm{~s}^{-1}$ every $6 \mathrm{~s}$ ) for $300 \mathrm{~s}$. Each mouse received 3 trials a day for 3 consecutive days. The latency to fall off the rotarod within this time period was recorded.

Dark-light box test. Each mouse was placed in an arena split into a lit compartment $(27 \times 27 \times 30 \mathrm{~cm})$, which was illuminated by a $60 \mathrm{~W}$ bulb $(\sim 400$ lux $)$ and a dark compartment $(18 \times 27 \times 30 \mathrm{~cm})$ with no light exposure. The two compartments were connected through an exit hole and the animal could move freely between compartments. Each tested animal was placed into the lit compartment facing away from the opening and allowed to freely explore the chambers for $10 \mathrm{~min}$. Total distance covered in the illuminated compartment, the time and number of visits to this compartment, as well as the latency to enter the dark compartment were recorded and analyzed.

\section{Tissue processing and immunostaining}

Under deep anesthesia, mice were perfused transcardially with ice-cold $0.25 \mathrm{mg} / \mathrm{ml}$ heparin in PBS $(10 \mathrm{ml})$, followed by PFA $4 \%(50 \mathrm{ml})$, and their brains thereafter harvested. For histological techniques, the brains were then postfixed overnight in PFA 4\% and incubated in sucrose (20\%) until total submersion, subsequently flash frozen in a cryomatrix embedding medium and stored at $-80^{\circ} \mathrm{C}$ until use. For histological (Nissl) and immunostaining procedures, postnatal specimens were cryosectioned at $25 \mu \mathrm{m}$ and tissue slices were processed as floating sections. Each forebrain coronal section from the bregma $1.1 \mathrm{~mm}$ (corresponding to the region showing the rostral tip of the corpus callosum genu) to bregma $-2.3 \mathrm{~mm}$ (corresponding to the region showing the caudal end of the caudo-putamen nuclei) was individually harvested in 48-well culture plates containing a cryopreservative (30\% sucrose, $1 \%$ polyvinylpyrrolidone, $30 \%$ ethylene glycol in TBS). For the selection and matching of control and conditional knock-out floating sections, these were carefully examined and compared under a stereomicroscope using sectionspecific neuroanatomical landmarks as delineated by the Franklin and Paxinos mouse brain atlas (Frankin and Paxinos, 2008). Accordingly, from the coronal section corresponding to bregma 0,5 tissue slices were sampled, each $500 \mu \mathrm{m}$ apart, thus providing specimens referring to 0 , $-0.5,-1,-1.5$, and $-2 \mathrm{~mm}$ bregma sections. For immunostaining, depending on antibody host species, the tissue was blocked with PBS solution containing of $0.1 \%$ Triton X-100, $1 \mathrm{~m}$ glycine, $1 \% \mathrm{BSA}$, and $10 \%$ goat or donkey serum. Primary antibody incubations were performed overnight at $4^{\circ} \mathrm{C}$ in PBS solution containing $0.1 \%$ Triton X-100 and $0.1 \%$ BSA. Secondary antibody incubations were performed at room temperature for $1 \mathrm{~h}$. We used 3,3'-diaminobenzidine (DAB)-based chromogenic methods for immunostaining procedures involving SST antibodies (Vector's peroxidase substrate and ABC kits, SK-4100 and PK-6100, respectively) following manufacturer instructions. Primary antibodies: choline-acetyltransferase (ChAT) (goat anti-ChAT, 1:1000, Millipore, catalog \#AB144), CR (rabbit anti-CR, 1:300, Thermo Fisher Scientific, catalog \#MA5-14540), DARPP32 (mouse anti-DARPP32, 1:100, Santa Cruz Biotechnologies, catalog \#271111), Foxp2 (rabbit anti-Foxp2, 1:50,
Santa Cruz Biotechnologies, catalog \#66897), GFAP (mouse anti-GFAP, 1:700, BD PharMingen, catalog \#556327), Htt (rabbit anti-Htt, 1:500, Cell Signaling Technologies, catalog \#5656), PV (mouse anti-PV, 1:300, Sigma-Aldrich, catalog \#P3086), Reln (goat anti-Reln, 1:500, R\&D Systems, catalog \#AF3820), and SST (rat anti-SST 1:500, Millipore, catalog \#MAB354). Alexa Fluor-conjugated secondary antibodies (Invitrogen) were diluted at 1:1500.

\section{Electron microscopy}

For electron microscopy techniques, perfused brains (see "Immunohistochemistry" section) were sliced ( $1 \mathrm{~mm}$ thick), fixed for an additional hour in a solution composed of $2 \%$ PFA and $2.5 \%$ glutaraldehyde in $0.1 \mathrm{M}$ cacodylate buffer, and then rinsed in this buffer. Samples were thereafter osmicated with $1 \%$ osmium tetroxide for $1 \mathrm{~h}$, rinsed in buffer, then water, and incubated with $2 \%$ uranyl acetate for $1 \mathrm{~h}$. Specimens were subsequently dehydrated in alcohol mixtures and embedded in Epon LX112.

\section{Image analyses}

Bright-field (Nissl and DAB staining) and fluorescent microscopic images were acquired on an Olympus BX51 fluorescence microscope/ Sensicam-PCO camera system. High-resolution microscopy in Figure 2, $C-F^{\prime}$, was performed on a Zeiss LSM880/Airyscan system. Neuronal species stained with Nissl were quantified in $34,450 \mu \mathrm{m}^{2}$ fields located in the dorsolateral aspect of the striatum in coronal sections corresponding to $0,-0.5,-1,-1.5$, and $-2 \mathrm{~mm}$ bregma locations. The density of cells throughout sample sections examined was then estimated using the NvVref stereological method (West, 1999). For motor cortex cellular quantifications, we used a region of interest (ROI) conforming to a 150$\mu \mathrm{m}$-wide column encompassing the cortical plate (from the external capsule white matter tract to the apical zone). For cellular quantifications within the striatum and GP, ROIs were obtained by outlining these nuclei closely following their contours using as a reference the Allen Brain Atlas (Allen Institute). The number of targeted cells were then quantified within each ROI and divided by the corresponding region to estimate density using ImageJ software (Schneider et al., 2012). Data per biological replicate from both hemispheres was averaged. For cell quantifications involving double labeling, immunostained cells were counted for each fluorescence channel separately and overlaid images were used to account for coexpression. Transmission electron microscopic photographs were acquired on a Jeol 1400/Gatan Orius SC1000B camera system. We examined two sections per block (two blocks per biological specimen, each corresponding to left and right subcortical nuclei) at a distance of $50 \mu \mathrm{m}$ from each other in the rostrocaudal axis mounted on $3.05 \mathrm{~mm}$ copper mesh grids. Within each copper grid, the four open areas of $10,400 \mu \mathrm{m}^{2}$ each clustered around the center mark of the grid were selected for the quantitation of degenerative cells. Cells with degenerative morphology were defined by the presence of electron-dense nucleus and cytoplasm, clumping of chromatin, swelling of the cisternae of the endoplasmic reticulum and of Golgi, and ruffling of the plasma membrane.

\section{Quantitative real-time PCR ( $q R T-P C R$ )}

We used qRT-PCR to study the efficiency of the CRE-mediated excisional recombination at the genomic level. To accomplish this goal, genomic DNA was purified using standard phenol: chloroform: isoamyl alcohol from striatal samples obtained by microdissection from tissue slices sectioned $250 \mu \mathrm{m}$ thick ( $n=8$ biological replicates per genotype). Thereafter, 100 pg of DNA was mixed with the PowerUP SYBR Green Master Mix (Applied Biosystems, catalog \#A25742) and run in an ABI 7000 Real-Time PCR system (Applied Biosystems) using primers targeting the floxed exon 3 region in $\mathrm{Htt}$ (forward: 5'-GTCATCAAAGTAAGCGCCCC-3'; reverse: 5'-CCAAGCCACATGCCCAAAAT-3') and the housekeeping gene, HPRT1 (forward: 5' -agcaggtgttctagtcctgtggc- $3^{\prime}$; reverse: $5^{\prime}$-gcgacaatctaccagagggtaggc- $\left.3^{\prime}\right)$. To reduce technical variability, each biological replicate was loaded as triplicates. Data collection and quality assessment were performed using 1.1 RQ Software (Applied Biosystems) and Statistical comparisons were made using the Pair Wise Fixed Reallocation Randomization test (PWFRR) (Pfaffl et al., 2002).

\section{Experimental design and statistical analyses}

Given the design similarities, we estimated our sample size based on our previous work using $\mathrm{Htt}$ hypomorph mice (Arteaga-Bracho et al., 2016). 


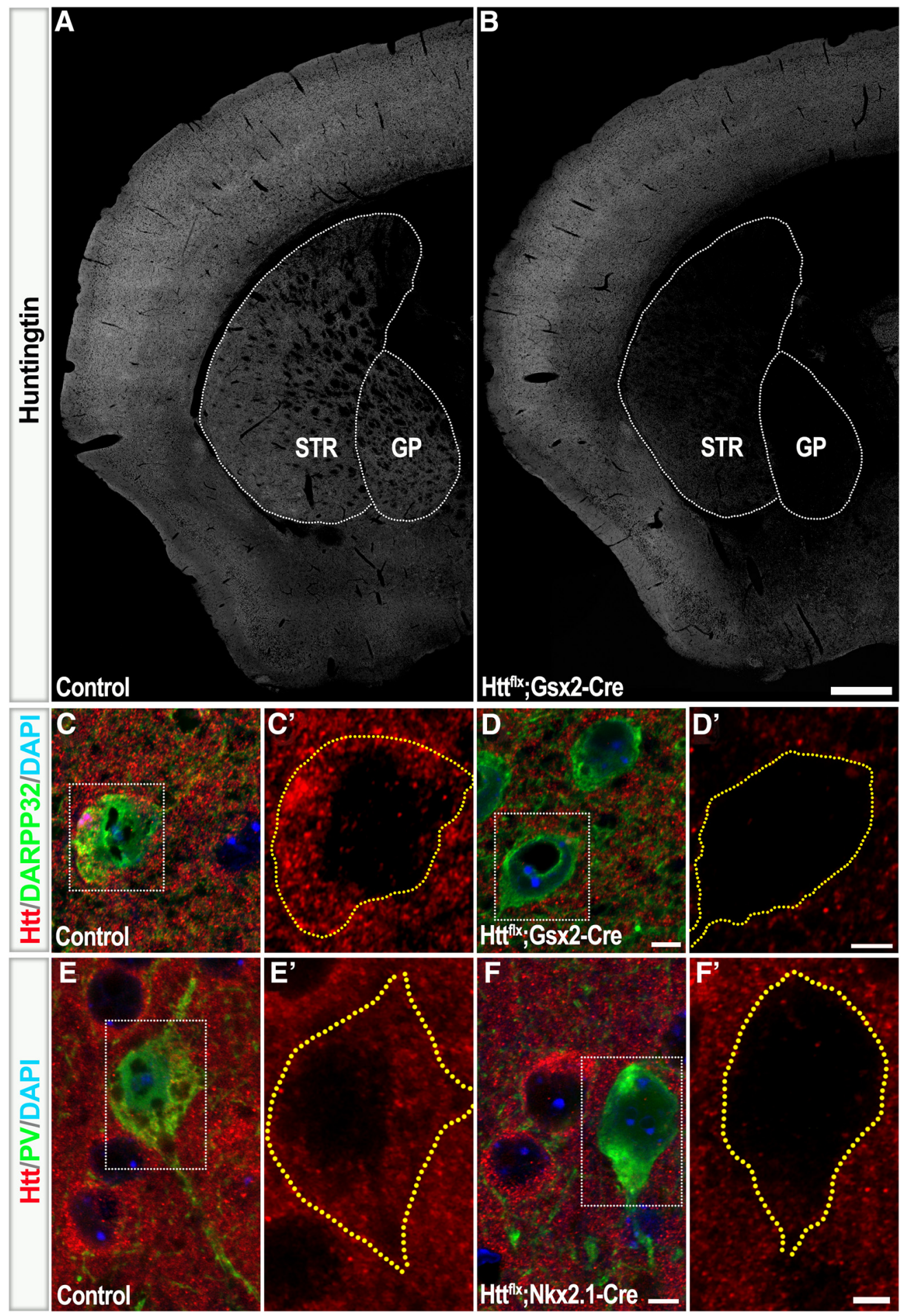

Figure 2. Cre expression from Gsx2 and Nkx2.1 promoters lead to excisional recombination of huntingtin in $\mathrm{Htt}{ }^{\mathrm{flx}}$ mice. $A, B$, Coronal sections of 1-month-old forebrains comparing the expression of huntingtin in the striatum (STR) and GP of control ( $\boldsymbol{A})$ and $\mathrm{Htt}^{\mathrm{ffx}}$;Gsx2-Cre (B) mice. $\boldsymbol{C}, \boldsymbol{D}$, Confocal microscopy sections immunostained against Htt and the MSN marker DARPP32. $\boldsymbol{C}^{\prime}, \boldsymbol{D}^{\prime}$, Higher-magnification areas of insets in $\boldsymbol{C}$ and $\boldsymbol{D}$, respectively, showing the differential expression of huntingtin within the cell body of control and $\mathrm{Htt}^{\mathrm{fl} x}$;Gsx2-Cre MSNs (outlined area). $\boldsymbol{E}, \boldsymbol{F}$, Tissue sections immunostained against $\mathrm{Htt}$ and the interneuron marker $\mathrm{PV}$ in 1-month-old striata of control and $\mathrm{Htt}{ }^{f l x} ; \mathrm{Nkx2}$.1-Cre mice. $\boldsymbol{E}^{\prime}, \boldsymbol{F}^{\prime}$, Higher-magnification areas of insets in $\boldsymbol{E}$ and $\boldsymbol{F}$, respectively, showing the differential expression of $\mathrm{Htt}$ within the cell body of control and $\mathrm{Htt}{ }^{\mathrm{flx}} ; \mathrm{Nkx2.1-Cre} \mathrm{PV}^{+}$interneurons (outlined area). Scale bars in $\boldsymbol{B}, \boldsymbol{D}-\boldsymbol{F}$, and $\boldsymbol{D}^{\prime}-\boldsymbol{F}^{\prime}$ represent 500,5 , and $3 \mu \mathrm{m}$, respectively.

Correspondingly, the effect size and variances from that study were calculated post hoc using $\mathrm{G}^{\star}$ Power software (Faul et al., 2009) and thereafter used as input to determine the minimal sample size required for behavioral and cellular comparisons at a statistical power of 0.8. Except for weight, because our initial analyses did not yield sex-specific differences, the sexes were pooled for further analyses. Mean comparisons between two independent experimental groups were performed using unpaired Student's $t$ tests, whereas for dependent experimental groups such as comparison between two time points, the two-tailed paired Student's $t$ test was used. Mean comparisons between more than two experimental groups were made with one-way ANOVA $F$ tests. Mean comparisons between experimental groups for the latency to fall over trial/time (ro- 
tarod) were performed using repeated-measures ANOVA F tests. Comparisons of weight over the time were done using regular two-way ANOVA $F$ tests. Mean comparisons of neurons throughout the rostrocaudal axis of experimental groups were performed using two-way ANOVA $F$ tests followed by the two-stage linear step-up BenjaminiKriger-Yekutieli (BKY) procedure to compare specific mutant versus control coronal sections. The rest of the post hoc analyses were performed using the Tukey's multiple-comparisons test (each $p$-value was adjusted to account for multiple comparisons). Analyses of proportions (e.g., percentage of degenerative cells, ZsGreen ${ }^{+}$cells) were accomplished with two-tailed $\chi^{2}$ tests and those of survival curves with the Mantel-Cox $\chi^{2}$ test. All statistical analyses were performed using GraphPad Prism software. Statistical tests were considered significant at a two-tail $p$-value $<$ 0.05 , with $p$-values, statistical test ( $t$ or $F$, for Student's $t$ test and ANOVA, respectively) and sample sizes $(n)$ reported in the Results section. Unless otherwise indicated, all mean variability measures correspond to SEM. All analyses were double blinded.

\section{Results}

\section{Generation of the conditional knock-out huntingtin models}

To generate the Htt-floxed mouse strain, we microinjected the C57BL/6N ESC clone EPD0635_1_E02, produced by homologous recombination by the EUCOMM/IKMC program (Skarnes et al., 2011), into blastocysts. The endogenous $\mathrm{Htt}$ gene (assembly GRCm38) in EPD0635_1_E02 ESC clones contains a loxP floxed exon 3 (ENSMUSE00000185595) plus an $F R T$-flanked $\beta$-galactosidase/neomycin cassette within intron 2 (Fig. 1A). Mice containing this gene construct were later identified by PCR among the progeny of chimeric specimens. To prevent any confounding effect associated with the presence of the $\beta$-Gal/Neo cassette in intron 2, this was excised by mating our mutant mice with flippase-expressing mice R26-FLPo (The Jackson Laboratory, catalog \#007844).

To conditionally ablate $\mathrm{Htt}$ in the lateral and medial ganglionic eminences (LGE and MGE, respectively) lineages, $\mathrm{Htt}^{\mathrm{flx}}$ mice were mated with Gsx2-Cre (The Jackson Laboratory, cata$\log \# 025856)$ and Nkx2.1-Cre (The Jackson Laboratory, catalog \#008661) mice, respectively. We confirmed that Cre recombination recapitulated the spatial profiles of the Gsx2 and Nkx2.1 progeny by mapping these lineages with an inducible reporter (RCL-ZsGreen; The Jackson Laboratory, catalog \#007906). Mapped cells in Gsx2-Cre;RCL-ZsGreen followed the typical spatial pattern for this lineage, with high reporter expression in the basal ganglia, where it mainly corresponds to oligodendrocytes and MSNs, and in the cortex, where it corresponds to oligodendrocytes and interneurons (Fig. 1B) (Kessaris et al., 2006; Fogarty et al., 2007). The high reporter expression within the Gsx2-Cre;RCL-ZsGreen GP was mainly accounted for by axonal projections from striatal MSNs. In a similar fashion, mapped cells in Nkx2.1-Cre;RCL-ZsGreen also followed the anticipated spatial pattern of the Nkx2.1 lineage, with a scattered profile within striatal and cortical areas corresponding to interneurons subtypes and enhanced expression within the GP, where a great number of neuronal species within this nucleus are labeled (Fig. 1C).

We further examined the expression of $\mathrm{Htt}$ in $\mathrm{Htt}^{\mathrm{flx}}$; $\mathrm{Gsx} 2$-Cre and $\mathrm{Htt}^{\mathrm{flx}} ; \mathrm{Nkx} 2.1$-Cre sections (Fig. 2). Although expression of $\mathrm{Htt}$ was greatly reduced in the basal ganglia of $\mathrm{Htt}^{\mathrm{flx}}$; Gsx2-Cre specimens, residual expression was still observed in the striatal parenchyma (Fig. 2A,B). Because Htt is pan-neuronally expressed and it is additionally found throughout all cellular compartments, including the axolemma and axon terminals, it is likely that residual expression of $\mathrm{Htt}$ in $\mathrm{Htt}^{\mathrm{flx}}$; Gsx2-Cre striata corresponds to neuronal projections from extrastriatal sources. Moreover, the striatum also contains non-Gsx2-derived cells, including interneurons and glial species actively expressing hun- tingtin. Therefore, to further confirm the absence of Htt in striatal MSNs, we performed high-resolution confocal microscopy in sections immunostained against $\mathrm{Htt}$ and the striatal MSN marker DARPP32 (Fig. 2C-D'). Accordingly, the expression of $\mathrm{Htt}$ was absent in $\mathrm{Htt}^{\mathrm{fl} x}$; Gsx2-Cre MSNs, thereby confirming the adequacy of the excisional recombination. Similarly, the expression of $\mathrm{Htt}$ was absent in $\mathrm{Htt}^{\mathrm{flx}}$; $\mathrm{Nkx} 2.1$-Cre cells expressing the interneuron marker PV (Fig. $2 E-F^{\prime}$ ), a neuronal lineage exclusively derived from the Nkx2.1 germinative zone. We further examined the efficiency of Cre-mediated excisional recombination using a qRT-PCR approach with primers targeting the floxed sequence within the huntingtin gene. To accomplish this goal, we collected DNA from adult $\mathrm{Htt}^{\mathrm{flx}}$; Gsx2-Cre striatal specimens using microdissection techniques $\left(n_{\text {per genotype }}=8\right)$. This genomic approach, in contrast to Western blot procedures, prevents the bias that is introduced by the source of Htt protein from extrastriatal axonal processes. Compared with controls, there was a $70 \%$ reduction in the quantity of amplicons generated from the floxed genomic region of $\mathrm{Htt}$ in the $\mathrm{Htt}^{\mathrm{flx}}$; $\mathrm{Gsx} 2$-Cre striatum (relative quantification $=0.31 \pm 0.25, p<0.0001$ ), thus providing additional evidence of proper levels of Cre-mediated recombination in our $\mathrm{Htt}^{\mathrm{flx}}$ mice. The remaining amplicon that was detected in $\mathrm{Htt}^{\mathrm{flx}}$; Gsx2-Cre specimens likely corresponds to lineages other than the Gsx2, including Nkx2.1-derived interneurons, Emx1-derived glial and neuronal species, microglia, and endothelial cells.

\section{Subpallial ablation of $\mathrm{Htt}$ differentially affects weight, seizure susceptibility, and survival}

Progressive body weight loss is one of the most characteristic features of HD. This is a consequence of a plethora of metabolic abnormalities, which include substantial hypothalamic alterations (Petersén and Björkqvist, 2006; van Wamelen et al., 2014). Because the Gsx2 and Nkx2.1 germinative niches contribute to several hypothalamic neuronal lineages and weight abnormalities have been reported in several HD models (Ferrante, 2009), we followed the weight of $\mathrm{Htt}^{\mathrm{flx}}$; Gsx2-Cre and $\mathrm{Htt}^{\mathrm{fl}}$; $\mathrm{Nkx} 2.1$-Cre mice throughout their first year of life. Measures of weight were comparable between 1-month-old control and mutant mice (Fig. $3 A, B)$; however, as the mice aged, clear differences distinguished these groups. $\mathrm{Htt}^{\mathrm{fl} x}$; Gsx2-Cre mice of each sex consistently exhibited age-dependent lower body weight than controls, particularly from the age of 8 months forward (genotype $\times$ age interaction, two-way ANOVA $F_{(9,135)}=2.003, p=0.043$ and $F_{(9,140)}=2.733, p=0.0057$ for male and females, respectively; Fig. $3 A$ ). Conversely, the weight deficits in $\mathrm{Htt}^{\mathrm{fl}}$; $\mathrm{Nkx} 2.1$-Cre mice proved to be greater and appeared earlier in both male (two-way ANOVA $\left.F_{(9,134)}=10.2, p=7.19 \mathrm{E}-12\right)$ and female (two-way ANOVA $F_{(9,148)}=33.6, p=1.44 \mathrm{E}-31$ ) mice compared with controls. However, $\mathrm{Htt}{ }^{\mathrm{flx}}$; $\mathrm{Nkx}$.1-Cre weight deficits seem to not worsen over the time (genotype $\times$ age interaction two-way ANOVA $F_{(9,148)}=0.718, p=0.693$ and $F_{(9,134)}=1.47, p=0.334$ for male and females, respectively; Fig. $3 B$ ). It is possible that this pattern of weight loss is exclusively explained by loss-of Htt function effects in subpallial-derived hypothalamic lineages and that, for the occurrence of further age-associated weight decline, the contribution of additional systemic metabolic factors is necessary (e.g., mitochondrial defects, skeletal muscle pathology).

Similar to our previous studies using mice expressing low levels of $\mathrm{Htt}$ only during development (Arteaga-Bracho et al., 2016), the ablation of $\mathrm{Htt}$ in either the Nkx2.1 or the Gsx2 cell lineage also led to handling-induced seizures. These were characterized by alternating clonic movements of forelimbs and head, facial 

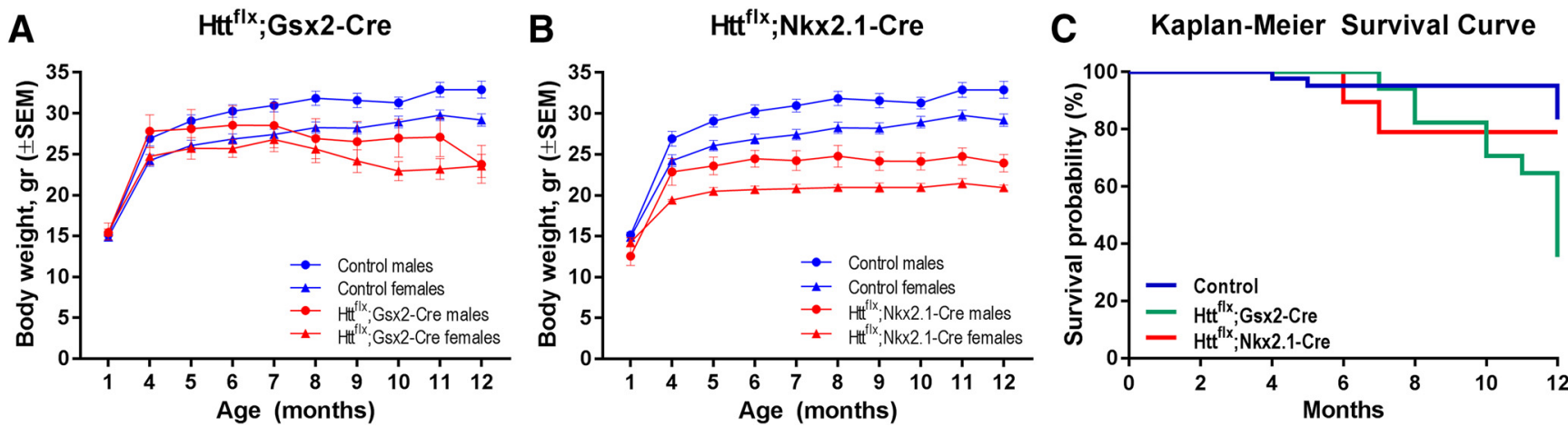

Figure 3. Ablation of huntingtin in subpallial lineages leads to age-dependent weight loss and premature death. $\boldsymbol{A}, \boldsymbol{B}, \mathrm{Graphs}$ comparing weight according to age and sex of Htt ${ }^{\text {flx }}$; Gsx2-Cre $(\boldsymbol{A})$ and $\mathrm{Htt}^{\mathrm{flx}}$;Nkx2.1-Cre (B) mice. $\boldsymbol{C}$, Comparative survival curves of experimental models throughout 12 months of life.

myoclonus, and flagpole tail dorsiflexion, followed by intermittent eye blinking, immobility, and head nodding. Among animals followed for 1 year, seizures were particularly frequent and severe in $\mathrm{Htt}^{\mathrm{flx}}$; $\mathrm{Nkx} 2.1-$ Cre mice $(63.1 \%, 12 / 19)$ compared with $\mathrm{Htt}^{\mathrm{flx}}$; Gsx2-Cre mice (10.5\%,2/19), whereas none was detected in controls (0/42). Interestingly, the R6/2 HD model, which display an aggressive and rapidly progressing phenotype, exhibit high predisposition to seizures (Parievsky et al., 2012). Moreover, epileptic seizures are a common comorbidity in juvenile forms of HD (Cloud et al., 2012).

Both $\mathrm{Htt}^{\mathrm{flx}}$; Gsx2-Cre and $\mathrm{Htt}^{\mathrm{flx}}$; Nkx2.1-Cre mice were obtained at the anticipated Mendelian ratios at birth and were later found to be viable and fertile. However, $\mathrm{Htt}^{\mathrm{flx}}$; Gsx2-Cre mice, but not $\mathrm{Htt}^{\mathrm{flx}}$; $\mathrm{Nkx} 2.1-\mathrm{Cre}$ mice, exhibited significantly higher mortality rates during adult life, with only $35.3 \%$ ( \pm 11.6 SEM), reaching 12 months of age, compared with $83.3 \%$ ( \pm 5.7 SEM) in controls (survival curve comparisons Mantel-Cox $\chi^{2}=14.9,1$ df, $p=0.0001$; Fig. 3C). Although seizure episodes have been linked to premature death in the R6/2 HD transgenic mouse model (Cepeda-Prado et al., 2012), it is unlikely that these explain the higher mortality rate in our conditional knock-out models because none of our mutant mice died after a handling-induced seizure episode and the death rates did not conform to the differential seizure frequencies, which were considerable higher in $\mathrm{Htt}^{\text {flx }}$;Nkx2.1-Cre mice compared with $\mathrm{Htt}^{\mathrm{flx}}$; Gsx2-Cre mice.

\section{Ablation of huntingtin in the Gsx2 and Nkx2.1 lineages result in motor deficits and anxiety-like behaviors}

Progressive deficits in motor functions are among the most debilitating neurological features of HD. Our previous studies have shown that pan-neural loss of Htt function during the murine developmental period leads to motor deficits and hyperkinetic phenotypes expressed during adult life (Arteaga-Bracho et al., 2016). Consistent with our findings, a more recent study reported that deletion of $\mathrm{Htt}$ in pallial lineages also results in hyperactivity and motor deficits (Dragatsis et al., 2018). To define whether the selective loss of Htt function in subpallial-derived lineages contribute to HD-like motor abnormalities, we examined motor coordination and free locomotion using the balance beam, rotarod and the open-field tests, respectively. Compared with controls, 12-month-old, but not younger, $\mathrm{Htt}^{\mathrm{flx}}$; Nkx2.1-Cre $\left(t_{(44)}=\right.$ 3.676; $p=0.0006 ; n=31$ control and 15 mutant) and $\mathrm{Htt}^{\mathrm{flx}}$; Gsx2-Cre $\left(t_{(39)}=5.954 ; p=5.99 \mathrm{E}-07 ; n=31\right.$ control and 10 mutant) mice exhibited a greater number of foot slips while traversing the elevated beam (Fig. $4 A$ ), suggesting age-dependent motor coordination deficits. At odds with the balance beam performance, 9-month-old and older $\mathrm{Htt}^{\mathrm{flx}}$; Gsx2-Cre mice para- doxically showed age-dependent increases in the latency to fall in the rotarod test compared with controls ( 9 months: $F_{(1,38)}=5.9$, $p=0.02, n=27$ control and 13 mutant; 12 months: $F_{(1,22)}=$ $16.4, p=0.0005, n=18$ control and 6 mutant; Fig. $4 B)$. However, the $\mathrm{Htt}^{\mathrm{flx}}$; Gsx2-Cre latency to fall at trial 1/day was comparable to that of controls (Tukey's multiple-comparisons test adjusted $p$-values $=0.924$ and 0.506 for 9 and 12 months of age, respectively), suggesting that rotarod performance in these mice likely resulted from compensatory mechanisms associated with motor learning (Feigin et al., 2006; Holtbernd et al., 2016). In addition to motor changes, both $\mathrm{Htt}^{\mathrm{flx}}$; Gsx2-Cre and $\mathrm{Htt}^{\mathrm{flx}}$; Nkx2.1-Cre mice exhibited very robust hyperkinetic phenotypes from the age of 3 months, as indicated by significant increases in the total distance traveled $\left(F_{(2,50)}=76.9 ; p=5.54 \mathrm{E}-16 ; n=16\right.$ control, $16 \mathrm{Htt}^{\mathrm{flx}}$; Nkx2.1-Cre and $7 \mathrm{Htt}^{\mathrm{flx}}$; Gsx2-Cre) and in associated locomotion speed $\left(F_{(2,36)}=32.45 ; p=8.77 \mathrm{E}-09\right.$; two-way ANOVA $)$ within the open field arena when compared with controls (Fig. 4C).

Neuropsychiatric symptoms, including anxiety, are commonly detected early during the premanifest phase of HD (Dale and van Duijn, 2015; Martinez-Horta et al., 2016; Ahveninen et al., 2018; Honrath et al., 2018). Moreover, anxiety-like behaviors are among the earliest and most robust traits observed in a diverse array of HD animal models (File et al., 1998; Hickey et al., 2008; Menalled et al., 2009; Renoir et al., 2011; Orvoen et al., 2012; Hult Lundh et al., 2013). Noteworthy, recent studies of HD patients have found a strong association between neuropsychiatric symptoms and deficits in the number of forebrain interneurons (Kim et al., 2014). As this cellular lineage derives from ventral Gsx2 and Nkx2.1 germinative niches, we examined for anxiety-like behaviors in our conditional null mice. The Open-field test showed that both $\mathrm{Htt}^{\mathrm{flx}}$; $\mathrm{Gsx} 2-\mathrm{Cre}$ and $\mathrm{Htt}^{\mathrm{flx}}$; $\mathrm{Nkx} 2$.1-Cre mice displayed strong thigmotaxis patterns (preferential locomotion along the peripheral walls of the arena), resulting in reductions in the time mice spent in the central region of the arena $\left(F_{(2,178)}=23.6 ; p=\right.$ 7.91E-10, Fig. $4 D, E)$. This locomotion pattern typically underlies anxious states (Simon et al., 1994). Thigmotaxis, though stronger at younger ages, remains detectable throughout the life of the mice. Consistently, both conditional knock-out strains also exhibited anxiety-like behaviors in the Dark-light box test, as indicated by shorter latency to enter the dark chamber $\left(F_{(2,53)}=\right.$ $6.973 ; p=0.002)$ and longer time spent in the dark chamber $\left(F_{(2,61)}=15.87 ; p=2.82 \mathrm{E}-06\right.$; Fig. $\left.4 F\right)$. The anxiety behavior in mutant mice is such that it acts to suppress the hyperkinetic phenotype associated with free locomotion, as is accounted for by the significant reduction in total distance traveled within the lighted arena of the dark-light box $(6.9 \pm 1.3,8.5 \pm 2.4$ and $21.9 \pm 2$ for $\mathrm{Htt}^{\mathrm{flx}}$; $\mathrm{Nkx} 2.1-\mathrm{Cre}, \mathrm{Htt}^{\mathrm{flx}}$; $\mathrm{Gsx} 2-\mathrm{Cre}$ and control 
A

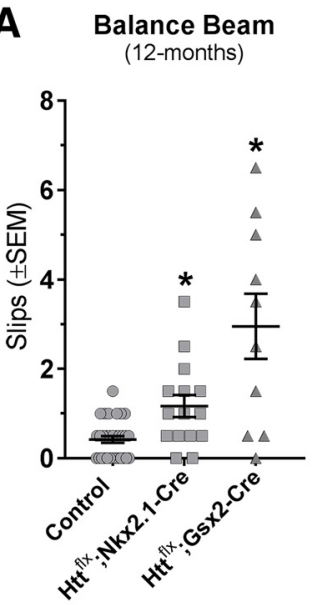

C

Open Field

(distance traveled)

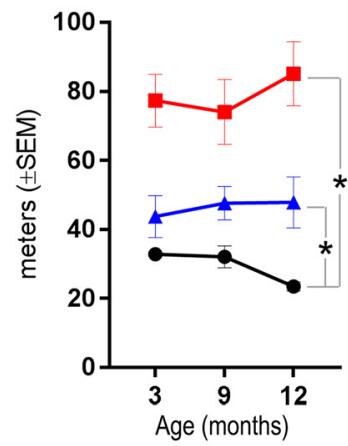

D

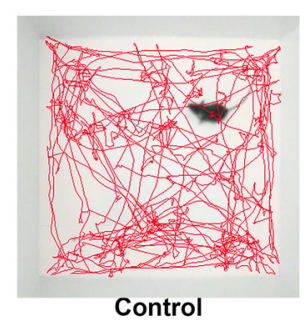

B Rotarod

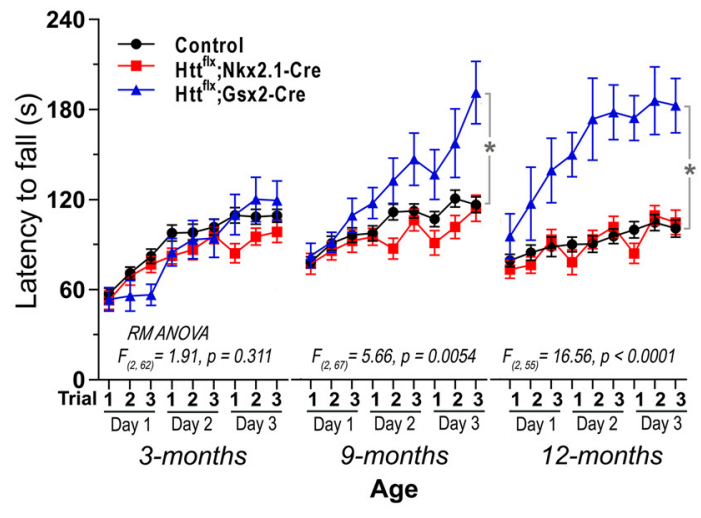

Open Field

(locomotion speed)

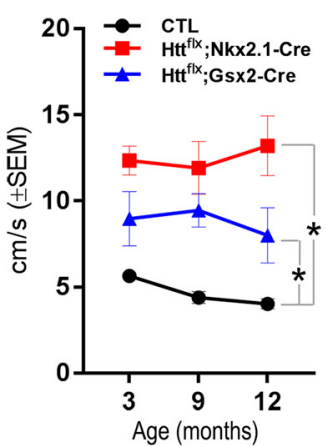

Open Field Arena (3-months)

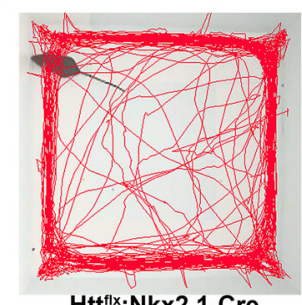

$\mathrm{Htt}{ }^{\mathrm{fl}} ; \mathrm{Nkx2}$.1-Cre

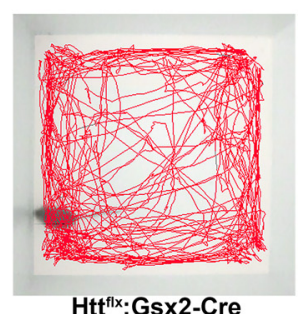

$\mathrm{Htt}^{\mathrm{fl}} ; \mathrm{Gsx} 2-\mathrm{Cre}$

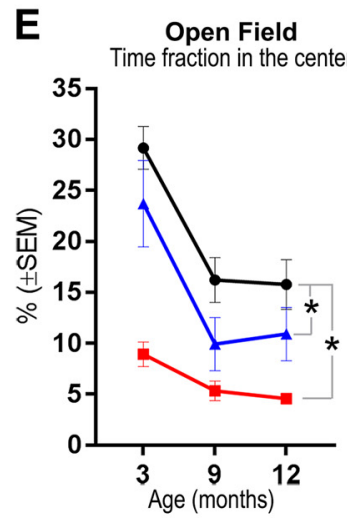

$\mathbf{F}$

Dark-Light Box (3-months)
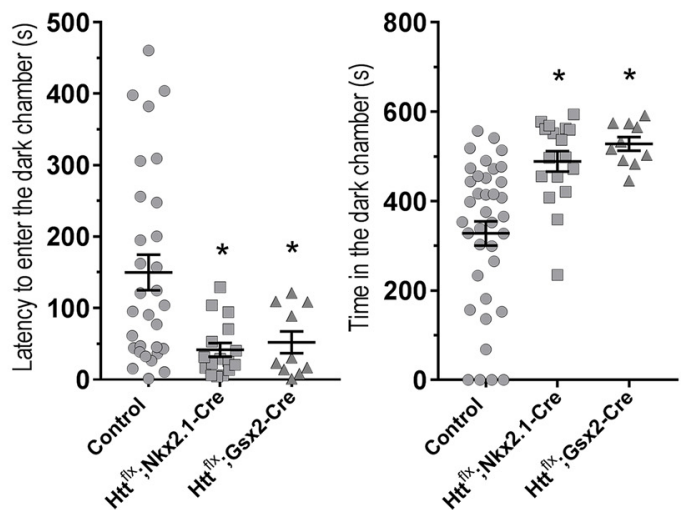

mice, respectively; $F_{(2,61)}=15.87 ; p=$ 2.82E-06). Overall, these findings demonstrate that selective loss of Htt in subpallial cellular species leads to a strong anxietylike phenotype.

\section{Ablation of huntingtin in subpallial lineages leads to late-onset degeneration in the basal ganglia but not in the cortex}

At 1 month of age, the striatal size, cellular density, and neurochemical compartmentalization (striosome vs matrix) was comparable between mutant $\left(\mathrm{Htt}^{\mathrm{flx}}\right.$; Gsx2-Cre and $\mathrm{Htt}^{\mathrm{flx}}$; $\mathrm{Nkx} 2.1-\mathrm{Cre}$ ) and control specimens. However, by 12 months of age, stereological studies based on Nissl staining of striatal coronal sections from bregma $0 \mathrm{~mm}$ to $-2 \mathrm{~mm}$ sections showed significant neuronal loss in $\mathrm{Htt}^{\mathrm{flx}}$; Gsx2-Cre mice compared with controls $(5.6 \mathrm{E}+3 \pm 0.2 \mathrm{E}+3$ vs $7.4 \mathrm{E}+3 \pm 0.4 \mathrm{E}+3$ neurons $\times \mathrm{mm}^{3}$, respectively; $t_{(9)}=4.02$, $p=0.0031 ; n=6$ mutant and 6 control). Striatal cell loss in $\mathrm{Htt}^{\mathrm{flx}}$; Gsx2-Cre specimens was limited to the caudal aspect of this nucleus (two-way ANOVA $F_{(1,45)}=$ 41.84, $p=6.28 \mathrm{E}-8$, two-stage BKY p-values $=0.31,0.11,0.28,0.002$ and 0.0001 for bregma sections $0,-0.5,-1,-1.5$, and $-2 \mathrm{~mm}$, respectively; Fig. $5 A, B, E$ ) and was accompanied by reductions in associated DARPP32 immunoreactivity (Fig. 5C,D). The degenerative process of the $\mathrm{Htt}^{\mathrm{flx}}$;Gsx2-Cre posterior striatum was accompanied by ex vacuo dilation of the lateral ventricles and intensive astrogliosis that was observed in all 12-monthold cases that we reviewed $(n=10)$, whereas none was observed among controls $(n=12)$ (Fig. $5 F, G)$. Similarly, our stereological analyses showed that 12month-old striatum of $\mathrm{Htt}^{\mathrm{flx}}$; $\mathrm{Nkx} 2.1-\mathrm{Cre}$ mice have fewer neuronal species compared with controls $(6.4 \mathrm{E}+3 \pm 0.3 \mathrm{E}+3$ vs $8.8 \mathrm{E}+3 \pm 0.5 \mathrm{E}+3$ neurons $\times \mathrm{mm}^{3}$, respectively; $t_{(8)}=3.49, p=0.0081 ; n=4$ mutant and 6 control). However, in contrast to $\mathrm{Htt}^{\mathrm{flx}}$; Gsx2-Cre specimens, neuronal cell loss was readily detected throughout the rostrocaudal axis of the $\mathrm{Htt}^{\text {flx }}$;Nkx2.1-Cre striatum (two-way ANOVA $F_{(1,40)}=31.57, p=1.62 \mathrm{E}-6$, two-stage BKY $p$-values $=0.036,0.0109$, $0.0037,0.0304$, and 0.0201 for bregma sections $0,-0.5,-1,-1.5$, and $-2 \mathrm{~mm}$,

Figure 4. Ablation of huntingtin in ventrally derived lineages leads to motor abnormalities and anxiety-like behaviors. $\boldsymbol{A}$, Number of slips (motor coordination) measured as the number of paw slips performed by 12-month-old mice while traversing the beam length of the balance beam test. $\boldsymbol{B}$, Rotarod performance/trial/d at 3-12 months of age. $\boldsymbol{C}$, Distance traveled and the average locomotion velocity of mice in the open-field test from 3 to 12 months of age. $\boldsymbol{D}, \boldsymbol{E}$, Representative tracing images of 3-month-old mice in the open-field arena $(\boldsymbol{D})$ and the fraction of time \pm SEM that these mice spent at the center of the arena $(\boldsymbol{E})$. $\boldsymbol{F}$, Graphs showing the latency exhibited by 3-month-old mice of entry for the first time into the dark chamber in the dark-light box test and

the amount of time these mice spent within this section. Each dot in graphs $\boldsymbol{A}$ and $\boldsymbol{F}$ corresponds to individual biological replicates. Experimental group categories depicted in $\boldsymbol{A}-\boldsymbol{C}, \boldsymbol{E}$, and $\boldsymbol{F}$ contain no $<10$ biological replicates each. ${ }^{*} p<0.001$. 

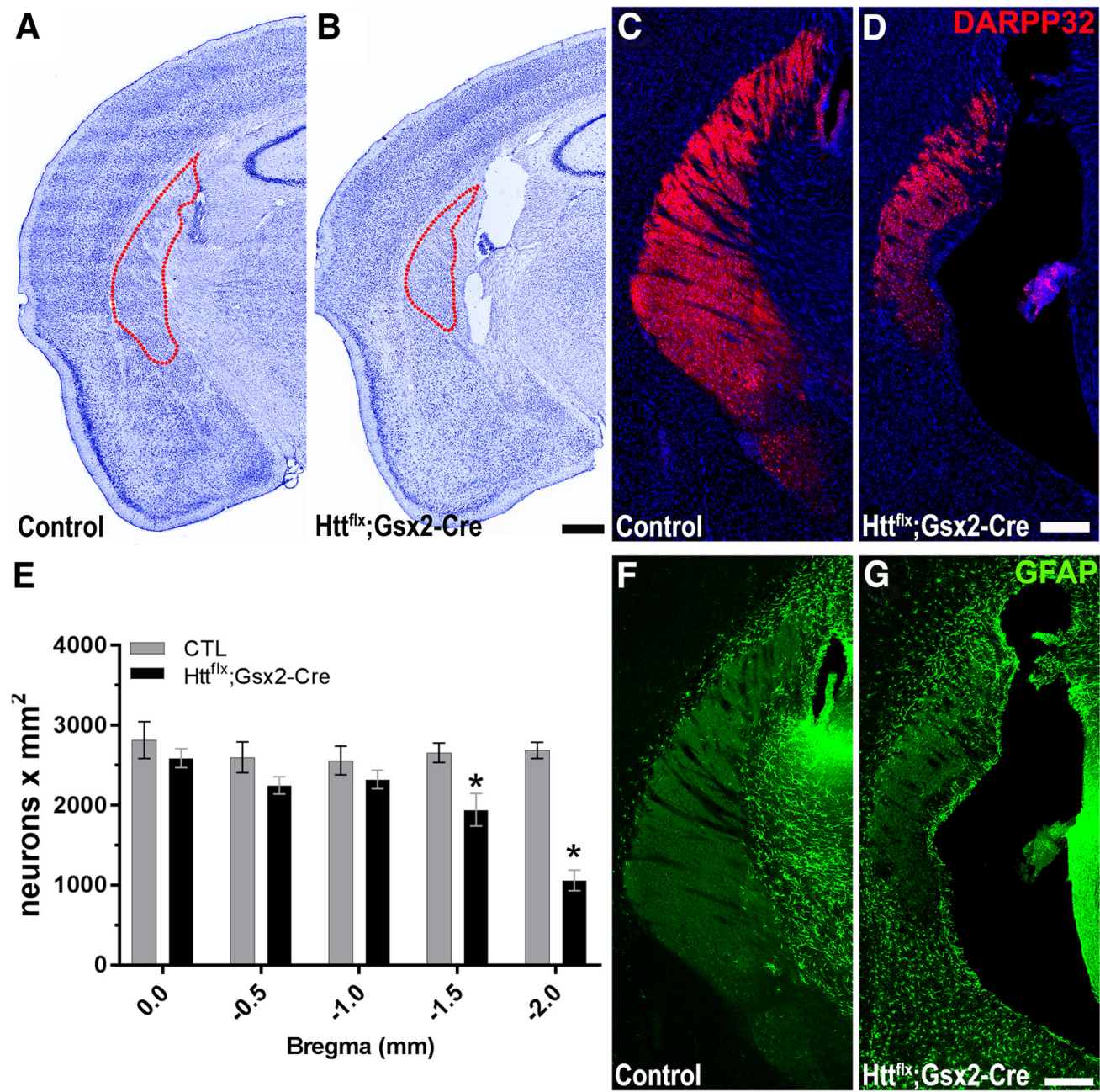

Figure 5. Absence of huntingtin in the Gsx2 lineage leads to late life neuronal loss in the caudal striatum. $A, B$, Coronal sections at bregma $-1.5 \mathrm{~mm}$ of 12 -month-old brains stained with Nissl. The striatum is outlined with dotted red line. $\boldsymbol{C}, \boldsymbol{D}$ and $\boldsymbol{F}, \boldsymbol{G}$ correspond to specimens of the same striatal region immunostained against DARPP32 and GFAP, respectively. $\boldsymbol{E}$, Graph comparing the average of neuronal species stained with Nissl at different bregma coronal sections. STR, Striatum; $L V$, lateral ventricle. $\ln E,{ }^{*} p<0.0001$. Scale bars in $A, B$ and $C, D, F, G$ correspond to 500 and 250 $\mu \mathrm{m}$, respectively.

respectively; Fig. 6A-C). Although cell loss in $\mathrm{Htt}^{\mathrm{flx}}$; $\mathrm{Nkx} 2.1$-Cre striatum was not as severe as that observed in the caudal $\mathrm{Htt}^{\mathrm{flx}}$; Gsx2-Cre striatum, this was accompanied by the presence of numerous cells showing the typical electron microscopy neurodegenerative morphology $\left(t_{(62)}=5.28, p=1.75 \mathrm{E}-06\right.$, pool of 16 fields/replicate, $n=2$ per genotype; Fig. $6 D-F)$. Moreover, $\mathrm{Htt}^{\mathrm{flx}}$; Nkx2.1-Cre specimens stained with Nissl also exhibited severe neuronal loss within the GP $(21.6 \pm 3.9$ vs $40.7 \pm 2.6$ neurons $\times$ $\mathrm{mm}^{2}$ for mutant and control, respectively; $t_{(10)}=4.01, p=$ $0.0025, n=6$ per genotype), which exhibited a significantly larger number of degenerative cells than in controls $\left(t_{(62)}=5.16, p=\right.$ 2.69E-06, pool of 16 fields/replicate, $n=2$ per genotype; Fig. $6 D$ ). Indeed, taking into account the differential neuronal density of the striatum versus GP (60 to 1, respectively), the latter exhibits greater degrees of neurodegeneration than the former. Interestingly, the $\mathrm{Htt}^{\mathrm{flx}}$; Nkx2.1-Cre GP not only shows neurons with typical degenerative morphology, but also neurons featuring numerous cytoplasmic vacuoles containing electron-dense granular cores or lamellar bodies, as well as vacuoles with amorphous electron translucent content (Fig. 6G-I), altogether characteristic cellular traits of granulovacuolar degeneration (Okamoto et al., 1991; Köhler, 2016). Moreover, we also observed the focal occurrence of multivesicular bodies within $\mathrm{Htt}^{\mathrm{flx}}$; Nkx2.1-Cre GP axonal processes, suggesting the existence of axonal spheroids.

Finally, we investigated whether the selective ablation of $\mathrm{Htt}$ in subpallial lineages has detrimental effects in the long-term survival of cortical neurons. At variance with the basal ganglia, the number of neuronal species per square millimeter counted with Nissl staining within the 12 -month-old motor cortex of $\mathrm{Htt}^{\mathrm{fl} x}$; Gsx2-Cre mice ( $2092 \pm 92$ vs $2223 \pm 138$ for control and mutant, respectively; $t_{(8)}=0.78, p=0.453, n=5$ per genotype) and $\mathrm{Htt}^{\mathrm{flx}} ; \mathrm{Nkx} 2.1$-Cre mice $(2966 \pm 118$ vs $3004 \pm 174$ for control and mutant, respectively; $t_{(8)}=0.179, p=0.862, n=5$ per genotype) was comparable to those in controls. Cortical pathology in HD is particularly more severe in the deep layers; therefore, to increase the sensitivity of our quantitative examinations, we focused on this region. In a similar fashion, our Nissl preparations did not identify differences within this cortical region between our null models and controls ( $\mathrm{Htt}^{\mathrm{flx}}$;Gsx2-Cre: $2184 \pm 127$ vs $2351 \pm 126 ; t_{(8)}=0.93, p=0.378 ; \mathrm{Htt}^{\mathrm{flx}} ; \mathrm{Nkx} 2.1$-Cre: $2990 \pm$ 116 vs $3055 \pm 113 ; t_{(8)}=0.401, p=0.698 ; n=5$ per genotype). Likewise, immunostaining against Foxp2, which in cortex selectively label pyramidal neurons within layer VI, neither detected differences between null models and controls $\left(\mathrm{Htt}^{\mathrm{flx}}\right.$;Gsx2-Cre: 
A

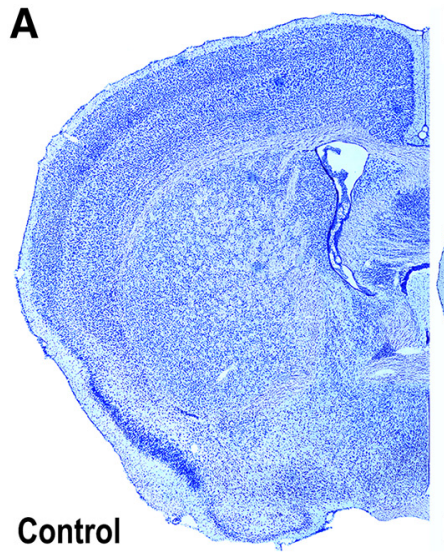

D

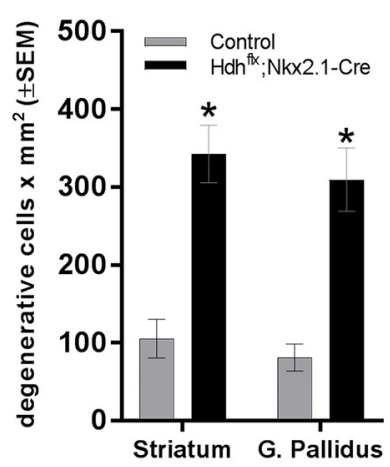

B

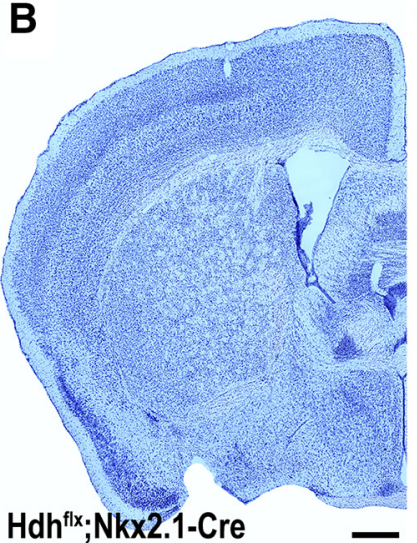

C

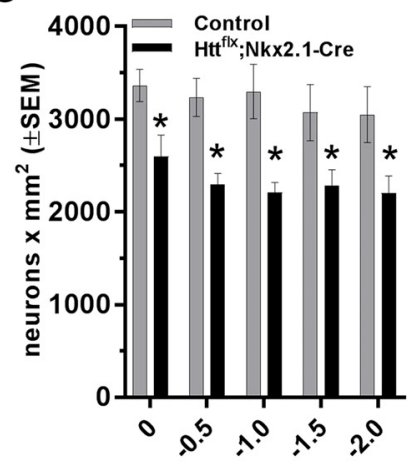

Bregma (mm)
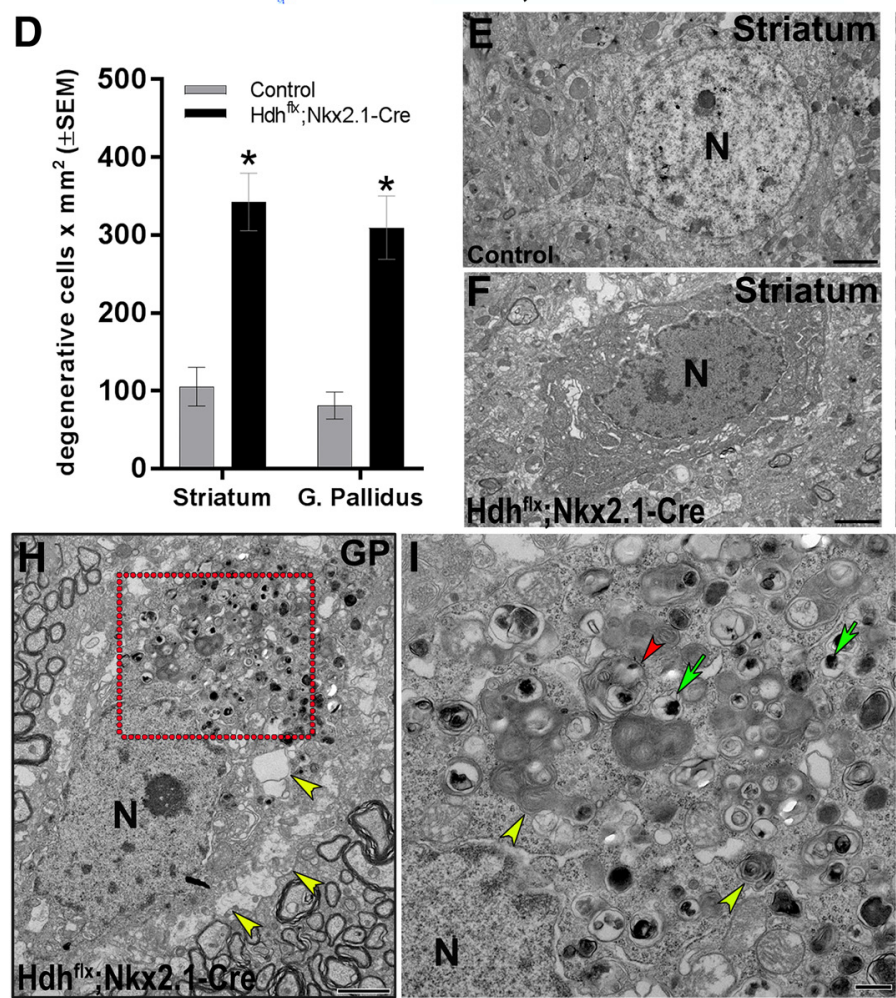
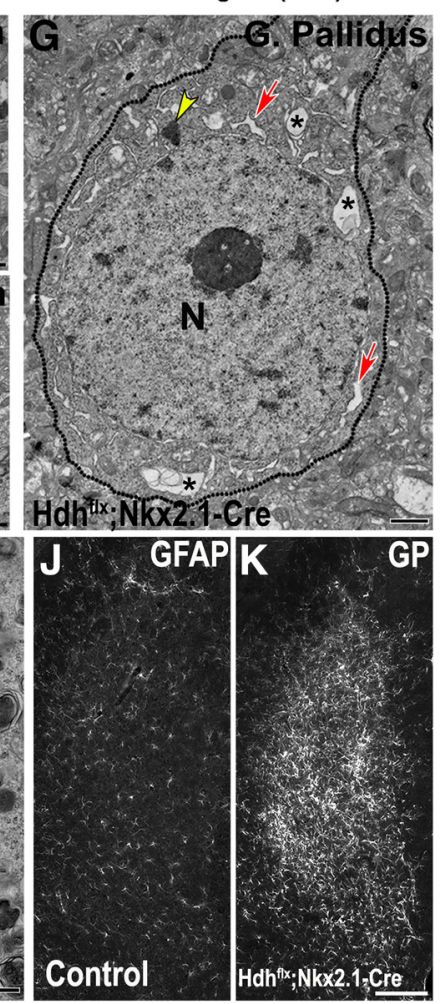

Figure 6. Absence of huntingtin in the Nkx2.1 lineage leads to late-life caudate and GP neurodegeneration. $\boldsymbol{A}, \boldsymbol{B}$, Coronal sections of 12-month-old brains stained with Nissl. C, Comparative analyses of the number of striatal neurons stained with Nissl at different bregma coronal sections. D, Comparative analyses of the number of striatal and GP degenerative neurons detected with electron microscopy. $\boldsymbol{E}, \boldsymbol{F}$, Representative normal and degenerative neurons, respectively. " $\mathrm{N}$ " in $\boldsymbol{E}-\boldsymbol{G}$ denotes the neuronal nuclei. Yellow arrowhead, red arrows, and asterisks in $\boldsymbol{G}$ and $\boldsymbol{H}$ denote electron-dense inclusions and swelling of the cisternae of the endoplasmic reticulum and of the Golgi, respectively. $\boldsymbol{I}$, Higher magnification of the outlined section in $\boldsymbol{H}$ showing in greater detail the ultrastructural features of granulovacuolar degeneration: cytoplasmic vacuoles containing electron dense core granules (green arrows), lamellar bodies (yellow arrowheads), as well as vacuoles with amorphous electrotranslucent content (red arrow). $\boldsymbol{J}, \boldsymbol{K}$, GFAP-immunostained coronal sections of the GP showing intense astrogliosis in Htt ${ }^{\text {flx }}$;Nkx2.1-Cre specimens. ${ }^{*} p<0.05$. Scale bars in $\boldsymbol{B}$, $\boldsymbol{E} / \mathbf{F} / \mathbf{H}, \mathbf{G}-\boldsymbol{I}$, and $\boldsymbol{K}$ correspond to $500,2,0.5$, and $250 \mu \mathrm{m}$, respectively.

$2100 \pm 136$ vs $2066 \pm 136 ; t_{(8)}=0.176, p=0.864 ; \mathrm{Htt}^{\mathrm{flx}} ; \mathrm{Nkx} 2.1-$ Cre: $2293 \pm 126$ vs $2457 \pm 61 ; t_{(8)}=1.17, p=0.275 ; n=5$ per genotype). Overall, these findings indicate that cell viability within the motor cortex of $\mathrm{Htt}^{\mathrm{flx}}$; Gsx2-Cre and $\mathrm{Nkx} 2.1-\mathrm{Cre}$ mice is not affected.

$\mathrm{Htt}^{\mathrm{flx}}$;Nkx2.1-Cre GP exhibits an aberrant complement of GABAergic neurons early in life and age-dependent loss of 'prototypical' neurons

The GP consists of two major GABAergic projection cell types, the "prototypic" neuronal type, which express PV, and the "arkypallidal" neuronal type, which express the transcription factor Foxp2 (Mallet et al., 2012; Abdi et al., 2015). Given the neu- ropathological changes observed in $\mathrm{Htt}^{\mathrm{flx}}$; $\mathrm{Nkx} 2.1$-Cre mice, we next interrogated the characteristics of these GABAergic cells using immunostaining techniques. At 1 month of age, there were no numerical differences in $\mathrm{PV}^{+}$prototypic neurons between conditions $\left(t_{(10)}=0.62, p=0.54, n=5\right.$ control and 7 mutants; Fig. $7 A, B, E)$. However, at this time, the density of $\mathrm{PV}^{+}$processes in the $\mathrm{Htt}^{\mathrm{flx}}$; Nkx2.1-Cre GP was greatly reduced (Fig. 7 F, G). Moreover, compared with 1-month-old specimens of the same genotype, 12-month-old $\mathrm{Htt}^{\mathrm{flx}}$; $\mathrm{Nkx}$ 2.1-Cre GP mice had significant fewer of $\mathrm{PV}^{+}$prototypical cells $\left(t_{(4)}=3.47, p=0.025, n=5\right.$ per genotype), as well as fewer $\mathrm{PV}^{+}$cells compared with agematched controls $\left(t_{(10)}=3.04, p=0.012 ; n=7\right.$ control and 5 mutant; Fig. $7 C-E)$. Furthermore, consistent with the electron 


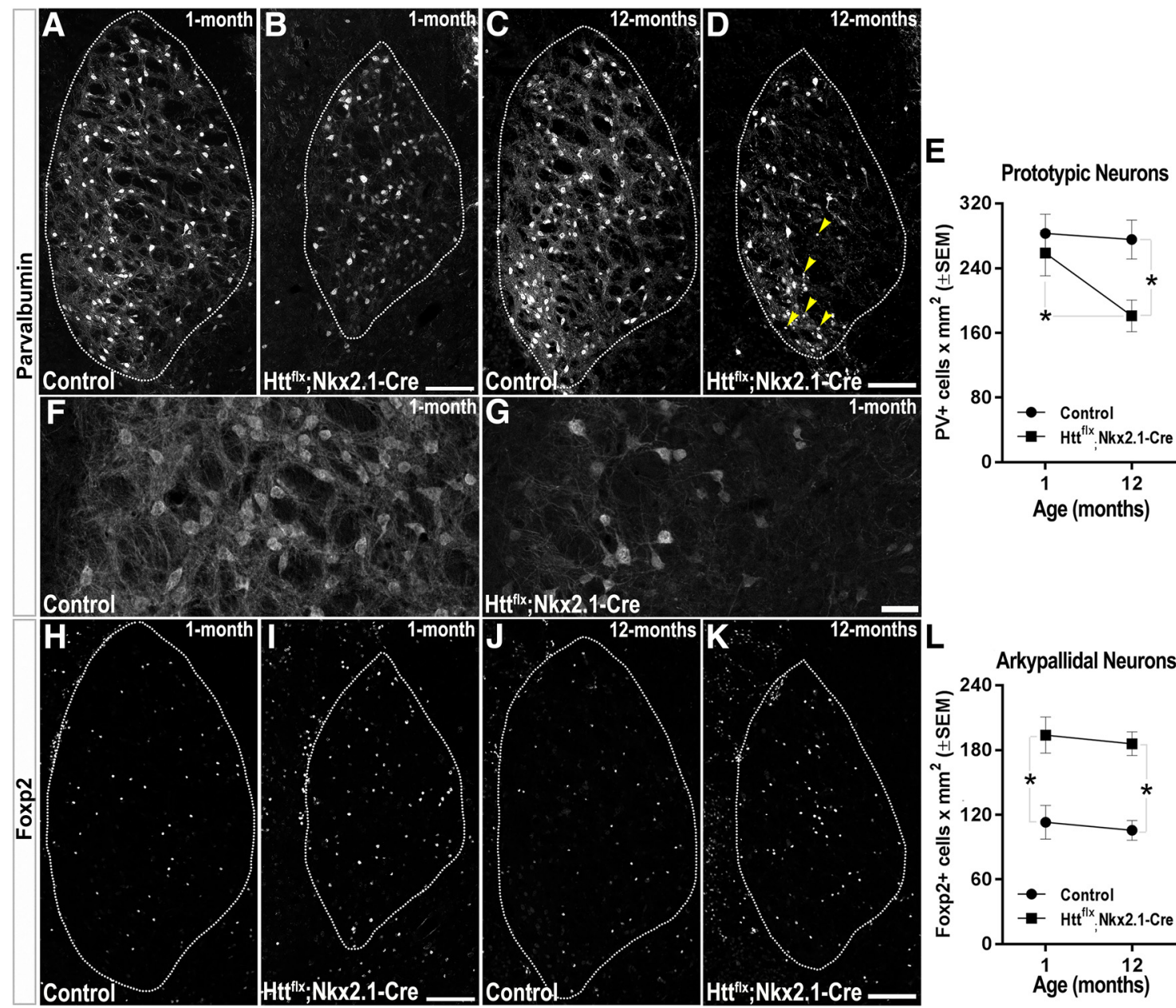

Figure 7. The GP of Htt ${ }^{\mathrm{fl}}$; Gsx2-Cre mice exhibit early changes in the complement of GABAergic neurons and age-dependent loss of PV ${ }^{+}$neurons. $\boldsymbol{A}-\boldsymbol{G}$ and $\boldsymbol{H}-\boldsymbol{K}$ depict coronal sections of 1-month-old $(\boldsymbol{A}, \boldsymbol{B}, \boldsymbol{F}, \boldsymbol{G}-\boldsymbol{I})$ and 12-month-old $(\boldsymbol{C}, \boldsymbol{D}, \boldsymbol{J}, \boldsymbol{K}) \mathrm{GP}$ sections immunostained against the prototypical neuron marker $\mathrm{PV}(\boldsymbol{A}-\boldsymbol{G})$ and the arkypallidal neuron marker Foxp2 $(\boldsymbol{H}-\boldsymbol{K})$. Arrowheads in $\boldsymbol{D}$ point to the abundant presence of spheroid bodies. $\boldsymbol{F}, \boldsymbol{G}$, Higher magnifications of the GP better depicting the reduction in $\mathrm{PV}^{+}$processes. $\boldsymbol{E}, \boldsymbol{L}$, Comparative analyses of prototypical and arkypallidal neurons, respectively. ${ }^{*} p \leq 0.01$. Scale bars in $\boldsymbol{B}, \boldsymbol{D}, \boldsymbol{I}$, and $\boldsymbol{K}$ correspond to $150 \mu \mathrm{m}$. Scale bar in $\boldsymbol{G}$ corresponds to $50 \mu \mathrm{m}$.

microscopic observations, $\mathrm{Htt}^{\mathrm{flx}}$; $\mathrm{Nkx} 2.1-\mathrm{Cre}_{\mathrm{PV}}{ }^{+}$cell processes appeared dystrophic, frequently displaying spheroid bodies (Fig. $7 D$, arrowheads). These data are indicative of age-dependent loss of $\mathrm{PV}^{+}$prototypical cells in $\mathrm{Htt}^{\mathrm{flx}} ; \mathrm{Nkx} 2.1$-Cre specimens.

Conversely, the number of arkypallidal Foxp $2^{+}$projection neurons in the 1-month-old GP of $\mathrm{Htt}^{\mathrm{flx}}$; $\mathrm{Nkx} 2.1$-Cre mice was significantly higher than in controls $\left(t_{(10)}=3.38, p=0.007 ; n=\right.$ 7 control and 5 mutant) and their number remained unaffected over time (Fig. $7 H-L$ ). This finding was not secondary to the possible reduction in size of the GP parenchyma associated with the decrease in $\mathrm{PV}^{+}$processes because corresponding raw data comparisons still showed these cells to be significantly elevated in $\mathrm{Htt}^{\mathrm{flx}}$; Nkx2 1 -Cre GP mice $(61.3 \pm 1.9$ vs $51.6 \pm 4.3$ cells, respectively, $\left.t_{(10)}=2.27, p=0.045\right)$. Previous studies have shown that GP arkypallidal cells derive from the LGE (Nóbrega-Pereira et al., 2010). Therefore, the observed increase complement of these cells after Htt ablation in the MGE-Nkx2.1 lineage suggests the occurrence of aberrant cell fate switches from $\mathrm{Nkx} 2.1$ neural stem/progenitor cells, non-cell-autonomous effects on LGE neurogenesis, or both. To begin to elucidate these possibilities, we fate-mapped GP Foxp $2^{+}$cells in $\mathrm{Htt}^{\mathrm{flx}}$; $\mathrm{Nkx} 2.1$-Cre mice using the RCL-ZsGreen reporter. Consistent with our observations, the number of Nkx2.1-lineage-derived Foxp $2{ }^{+}$arkypallidal cells did not differ between 1-month-old controls and $\mathrm{Htt}^{\text {flx }}$; Nkx2.1-Cre specimens $\left(12.1 \pm 2.5, n=5\right.$, vs $22.8 \pm 5.6, n=7$, cells $\times \mathrm{mm}^{2}$, respectively; $\left.t_{(10)}=1.54, p=0.154\right)$. Therefore, the increase of Foxp $2^{+}$cells in $\mathrm{Htt}^{\mathrm{flx}}$; Nkx2.1-Cre mice is likely associated with non-cell-autonomous mechanisms. Interestingly, at odds with a previous literature report (Dodson et al., 2015), we found that the Nkx2.1 lineage actually contributes $\sim 10 \%$ of Foxp $2^{+}$arkypallidal cells $(10.02 \%, 95 \%$ confidence interval $=5.7-14.3)$. Interestingly, the fraction of Foxp $2^{+}$arkypallidal cells was comparable between $\mathrm{Htt}^{\mathrm{flx}}$; $\mathrm{Nkx} 2.1$-Cre and control specimens.

Loss of huntingtin in the $\mathrm{Nkx} 2.1$ lineage leads to age-dependent loss of striatal and cortical $\mathrm{PV}^{+}$cells

We next investigated whether $\mathrm{Htt}^{\mathrm{flx}}$; $\mathrm{Nkx} 2.1$-Cre GP changes in $\mathrm{PV}^{+}$cells extended to other forebrain areas. Compared with controls, the 1-month-old striatum and motor cortex of $\mathrm{Htt}^{\mathrm{flx}}$; Nkx2.1-Cre mice exhibited a comparable number of $\mathrm{PV}^{+}$ neurons (striatum: $t_{(11)}=1.55, p=0.15, n=9$ control and 4 mutant; cortex: $t_{(15)}=1.14, p=0.27, n=11$ control and 6 mutant; Fig. $8 A, C-E, H)$. However, compared with controls, the number of $\mathrm{Htt}^{\mathrm{flx}}$; $\mathrm{Nkx} 2.1-\mathrm{Cre} \mathrm{PV}^{+}$cells decreased significantly within these areas at 12 months of age (striatum: $t_{(11)}=7.78, p=$ $8.5 \mathrm{E}-06, n=8$ control and 5 mutant; cortex: $t_{(14)}=2.72, p=$ $0.016, n=11$ control and 5 mutant). Interestingly, the loss of $\mathrm{Htt}^{\mathrm{flx}}$;Nkx2.1-Cre cortical $\mathrm{PV}^{+}$neurons in motor areas occurred 

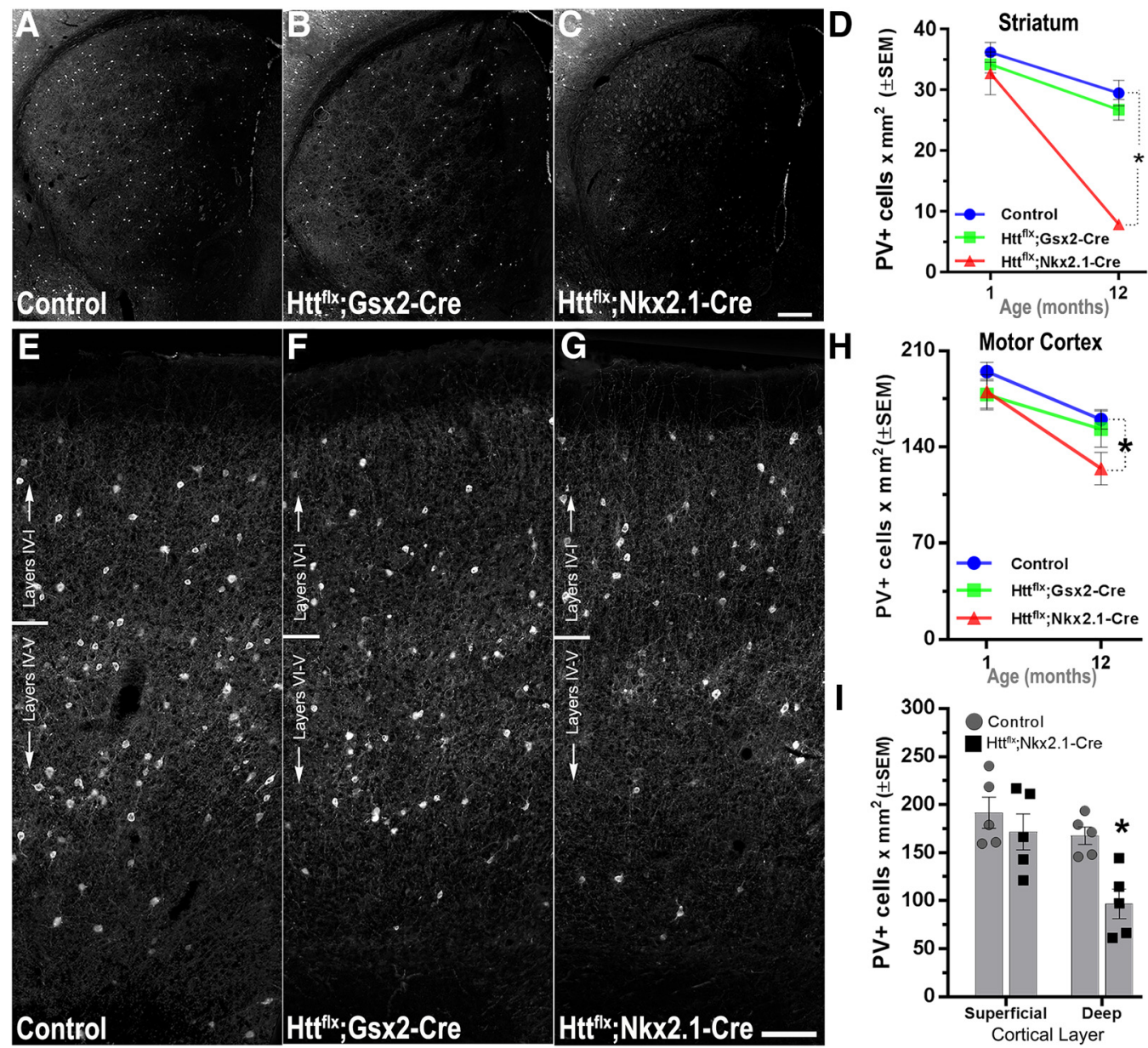

Figure 8. Ablation of huntingtin in the Nkx2.1 lineage leads to age-dependent loss of striatal and cortical PV ${ }^{+}$neurons. $\boldsymbol{A}-\mathbf{C}$ and $\boldsymbol{E}-\mathbf{G}$ depict coronal sections of 12 -month-old striatum and motor cortex, respectively, stained against PV.D, H, Comparative analyses of the number of PV ${ }^{+}$cells in cross-sections of the striatum and motor cortex at bregma $0.5 \mathrm{~mm} . I$, Graph showing that reductions in $\mathrm{Htt}^{\mathrm{flx}} ; \mathrm{Nkx2.1-Cre} \mathrm{cortical} \mathrm{PV}{ }^{+}$neurons selectively occur in the deep layers. In $\boldsymbol{D}, \boldsymbol{H}, \mathbf{I},{ }^{*} p<0.05$. Scale bars in $\mathbf{C}$ and $\mathbf{G}$ correspond to 300 and $100 \mu \mathrm{m}$, respectively.

at the expense of changes in deep layers $\left(t_{(8)}=3.86, p=0.0048\right.$, $n=5$ per genotype; Fig. $8 I$ ), whereas those located in superficial layers appeared undisturbed $\left(t_{(8)}=0.88, p=0.403, n=5\right.$ per genotype; Fig. $8 I$ ). We also investigated whether the ablation of $\mathrm{Htt}$ in the Gsx2 lineage disrupts the population of forebrain $\mathrm{PV}^{+}$ cells and no differences were detected between $\mathrm{Htt}^{\mathrm{flx}}$; Gsx2-Cre and control mice (Fig. $8 A, B, D-F, H$ ).

Ablation of huntingtin in Nkx2.1- and Gsx2-derived lineages differentially disrupts the number of SST, cholinergic, and CR striatal and cortical interneurons

Previous studies have shown that forebrain SST interneurons are derived from both the Nxk2.1 and Gsx2 subpallial lineages. We investigated whether Htt plays a role in the neurogenesis and viability of these cells. Although, at 1 month of age, the ablation of $\mathrm{Htt}$ does not have any effect on the number of striatal $\mathrm{Htt}^{\mathrm{flx}}$; Nkx2.1-Cre SST ${ }^{+}$interneurons $\left(t_{(14)}=1.99, p=0.065, n=10\right.$ control and 6 mutant; Fig. $9 A, C, G)$, the number of these cells was significantly lower in matching $\mathrm{Htt}^{\mathrm{flx}}$; Gsx2-Cre mice $\left(t_{(13)}=\right.$ 7.38, $p=5.34 \mathrm{E}-06, n=10$ control and 5 mutant; Fig. $9 A, B, G)$. Given the dual Nxk2.1 and Gsx2 lineage origin of SST ${ }^{+}$cells, we investigated whether compensatory increases from the nonNkx2.1-derived $\mathrm{SST}^{+}$lineage explains the lack of differences among 1-month-old $\mathrm{Htt}^{\mathrm{fl}}$; $\mathrm{Nkx} 2.1$-Cre specimens. To accomplish this goal, we traced the Nkx2.1 lineage with the ZsGreen reporter and further compared the number of SST ${ }^{+}$interneurons after Htt ablation in Nkx2.1-derived cells. This approach revealed not only that the number of $\mathrm{Htt}^{\mathrm{flx}}$; $\mathrm{Nkx} 2.1-\mathrm{Cre} \mathrm{SST}^{+}$ interneurons from an $\mathrm{Nkx} 2.1$ origin was significantly lower compared with those in controls $(12.8 \pm 0.5$ vs $23.9 \pm 1.5$ cells $X$ $\mathrm{mm} 2$, respectively; $t_{(9)}=6.96, p=6.61 \mathrm{E}-05, n=5$ per genotype), but also that the number of non-Nkx2.1-derived SST ${ }^{+}$interneurons increased by $61 \%$ in $\mathrm{Htt}^{\mathrm{flx}}$; $\mathrm{Nkx} 2.1$-Cre compared with controls $\left(16.42 \pm 1.3\right.$ vs $10.2 \pm 0.3$ cells $\times \mathrm{mm}^{2}$, respectively; $t_{(9)}=$ 5.33, $p=0.0007, n=5$ per genotype). This indicates that, although ablation of Htt in the Nkx2.1 lineage similarly disrupts neurogenesis of striatal SST ${ }^{+}$cells, their numbers remain stable due to compensatory increases from an alternate lineage. Interestingly, the ablation of $\mathrm{Htt}$ in the Gsx2 lineage was not associated with compensatory responses from other lineages. Rather, it appears that this genetic manipulation repressed somatostatinergic neurogenesis from the $\mathrm{Nkx} 2.1$ lineage $(4.96 \pm 0.83$ vs $9.44 \pm 0.4$ cells $\times \mathrm{mm}^{2}$, from mutant and control, respectively; $t_{(7)}=4.6$, $p=0.0007, n=4$ control and 5 mutant), further exacerbating the deficit of striatal SST ${ }^{+}$cells

In the motor cortex, the number of SST ${ }^{+}$interneurons was significantly lower in both 1 -month-old $\mathrm{Htt}^{\text {flx }}$; Gsx2-Cre mice $\left(t_{(14)}=2.68, p=0.017, n=11\right.$ control and 5 mutant $)$ and $\mathrm{Htt}^{\mathrm{flx}} ; \mathrm{Nkx} 2.1$-Cre mice $\left(t_{(15)}=4.11, p=0.0009, n=11\right.$ control and 6 mutant) than in controls (Fig. 9D-F,H). The decrease in 
cortical Nkx2.1 SST ${ }^{+}$interneurons was not accompanied by compensatory increases of SST ${ }^{+}$cells from other lineages $t_{(9)}=0.02, p=0.98, n=6$ control and 5 mutant). Moreover, contrary to Htt-null $\mathrm{PV}^{+}$cells, the ablation of $\mathrm{Htt}$ in $\mathrm{SST}^{+}$interneurons did not affect the long-term survival of these cells in the striatum or cortex (Fig. 9G,H).

Cholinergic neurons represent another major cellular subtype derived from the Nkx2.1 germinative zone. We examined these cells by using the cholinergic marker ChAT. Compared with controls, the ablation of Htt in Nkx2.1-derived cells led to an aberrant increase in the number of striatal $\left(t_{(8)}=4.58, p=0.0018, n=5\right.$ per genotype) and GP $\left(t_{(6)}=4.33, p=\right.$ $0.0049, n=4$ per genotype) $\mathrm{ChAT}^{+}$cells within the 1-month-old basal ganglia (Fig. 10). Moreover, control and $\mathrm{Htt}^{\mathrm{flx}}$; Nkx2.1-Cre mice displayed a comparable number of $\mathrm{ChAT}^{+}$projection neurons within the 1-month-old nucleus of Meynert (71.2 \pm 3.6 vs $62.8 \pm 3.24$, respectively, $t_{(8)}=1.73, p=0.121, n=5$ per genotype), thus indicating that Htt associated deficits are cell-type and region specific, predominantly circumscribed to cholinergic interneurons subtypes. Moreover, no differences were observed between 12-month-old control and $\mathrm{Htt}^{\mathrm{flx}}$; Nkx2.1-Cre cholinergic cells.

We also performed a parallel series of immunostaining paradigms to define the effects of Htt ablation in $\mathrm{CR}^{+}$interneurons. In contrast to other interneuron subtypes, no remarkable differences were observed in the number of $\mathrm{CR}^{+}$interneurons in the cortex and striatum of either 1or 12-month-old $\mathrm{Htt}^{\mathrm{flx}}$; Gsx2-Cre and $\mathrm{Htt}^{\mathrm{flx}}$; Nkx2.1-Cre mice. However, when considering the subpopulation of $\mathrm{CR}^{+}$ interneurons also expressing SST (CR/ $\mathrm{SST}^{+}$), the striatum of 1-month-old $\mathrm{Htt}^{\mathrm{flx}}$;Gsx2-Cre mice exhibited a reduced complement of these cells compared with controls $(0.56 \pm 0.2$ vs $2.56 \pm 0.3$, respectively, $t_{(13)}=5.12, p=0.0002, n=10$ control and 5 mutant). These findings further emphasize that the roles of $\mathrm{Htt}$ in interneuron neurogenesis are both cell lineage of origin- and interneuron subtype-context specific.
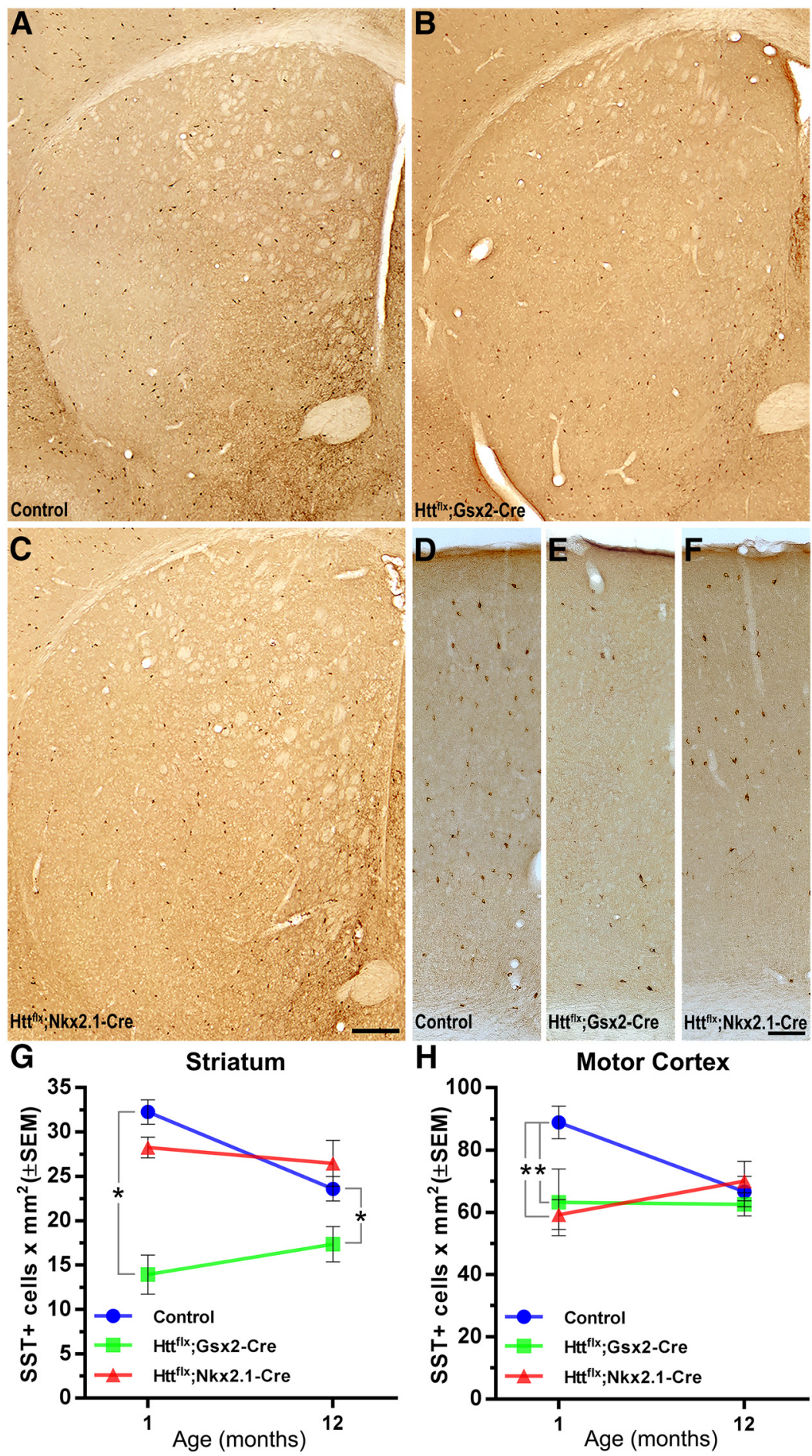

Figure 9. Ablation of huntingtin in the Nkx2.1 and Gsx2 lineages lead to both selective early and late changes in the complement of striatal and cortical $S S T^{+}$neurons. $\boldsymbol{A}-\boldsymbol{F}$, Coronal sections at bregma $0.5 \mathrm{~mm}$ of the 1 -month-old striatum $(\boldsymbol{A}-\boldsymbol{C})$ and motor cortex (D-F) immunostained against SST. $\mathbf{G}, \boldsymbol{H}$, Graphs comparing the number of SST ${ }^{+}$cells in the striatum and motor cortex, respectively. In $\boldsymbol{G}, \boldsymbol{H},{ }^{*} p<0.05$. Scale bars in $\boldsymbol{C}$ and $\boldsymbol{F}$ correspond to 250 and $100 \mu \mathrm{m}$, respectively.

\section{Ablation of huntingtin in Nkx2.1- and Gsx2-derived interneurons negatively affects the number of cortical Reelin-positive $\left(\operatorname{Reln}^{+}\right)$cells}

Previous studies have demonstrated that Reln, a glycoprotein with seminal roles in modulating numerous milestones of neuronal network development, is expressed postnatally in striatal and cortical GABAergic neurons (Pesold et al., 1998; Sharaf et al., 2015). We therefore examined the effects of Htt ablation on Reln expression using immunostaining techniques. Reln was highly expressed throughout the striatum of both control and mutant specimens because this protein is expressed by all MSNs. However, the motor cortex of 1-month-old $\mathrm{Htt}^{\mathrm{flx}}$; Gsx2-Cre $\left(t_{(13)}=\right.$ 3.04, $p=0.0096, n=10$ control and 5 mutant) and $\mathrm{Htt}^{\mathrm{flx}}$; Nkx2.1-Cre $\left(t_{(14)}=9.571, p=1.6 \mathrm{E}-07, n=10\right.$ control and 6 mutant) mice exhibited fewer Reln ${ }^{+}$cells than in controls (Fig. $11 A-D)$. Admittedly, although the reduction in cortical Reln ${ }^{+}$ 

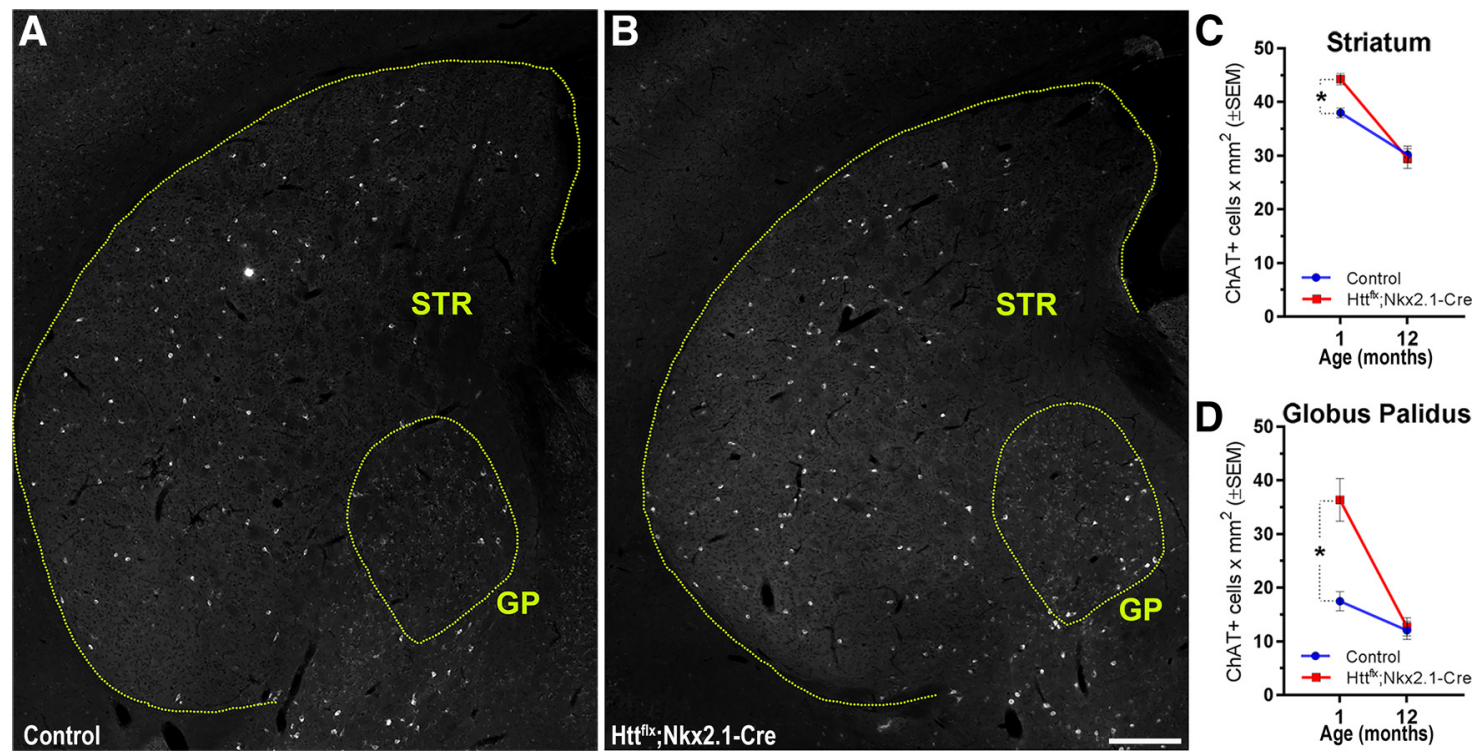

Figure 10. Basal ganglia of $\mathrm{Htt}{ }^{\mathrm{flx}}$;Nkx2.1-Cre mice show an early increase of cholinergic interneurons. $\boldsymbol{A}, \boldsymbol{B}$, Coronal sections immunostained against ChAT in 1-month-old basal ganglia structures: the striatum (STR) and the GP. C, D, Comparative analyses of ChAT ${ }^{+}$cells at 1 and 12 months of age. In $\boldsymbol{C}, \boldsymbol{D},{ }^{*} p<0.005$. Scale bar in $\boldsymbol{B}$ corresponds to $300 \mu \mathrm{m}$.

cell is largely a consequence of the decrease in GABAergic interneurons, it is also possible that the expression of this protein is compromised among Htt-null cells in each corresponding lineage. To interrogate this possibility, we quantified the number of Reln ${ }^{+}$cells within each lineage using the ZsGreen reporter system. In the event that reductions of Reln ${ }^{+}$cells are only a consequence of the presence of fewer GABAergic interneurons, we anticipated no differences between mutant and control specimens with regard to the number of double Reln/ZsGreen ${ }^{+}$cells. Instead, we observed that the number of cells expressing Reln ${ }^{+}$ within either the Gsx2 or Nkx2.1 lineage was significantly lower than in controls ( $\mathrm{Htt}^{\mathrm{flx}}$; Gsx2-Cre;RCL-ZsGreen mice: $t_{(7)}=3.79$, $p=0.0067, n=4$ control and 5 mutant; $\mathrm{Htt}^{\mathrm{flx}}$; Nkx2.1-Cre;RCLZsGreen mice: $t_{(10)}=5.93, p=0.00014, n=6$ per genotype; Fig. $11 E, F)$. These findings suggest that, in addition to the reductions of interneurons, Reln deficits in Htt null mice are also the consequence of impairments in the expression of this glycoprotein among remaining interneurons.

\section{Discussion}

Emerging studies from our group and others have shown that HD has an important neural developmental component, likely associated with loss-of-function mechanisms, that contributes to disease pathogenesis (Kerschbamer and Biagioli, 2015; ArteagaBracho et al., 2016; Molero et al., 2016; Siebzehnrübl et al., 2018). However, to date, the cellular substrate and mechanistic underpinnings of this developmental component have remained elusive. In this study, we have interrogated whether loss-of-Htt function within the cellular progeny derived from two main subpallial (Gsx2 and Nkx2.1) neural lineages account for the occurrence of key neurological hallmarks of HD. Despite the differences between these lineages, the ablation of Htt similarly resulted in a common spectrum of HD hallmarks (motor and neuropsychiatric abnormalities as well as basal ganglia neuropathology). These findings are consistent with our previous study based on the use of a genetic model with loss-of-Htt function restricted to the neurodevelopmental period (Arteaga-Bracho et al., 2016). In agreement with but extending the findings of this model, the selective ablation of $\mathrm{Htt}$ in $\mathrm{Htt}^{\mathrm{flx}}$; Gsx2-Cre and $\mathrm{Htt}^{\mathrm{flx}}$;
Nkx2.1-Cre mice similarly reproduces key HD features, strongly indicating that HD-like phenotypes are a consequence of developmental alterations rather than as a result of the ongoing effects of the continuous absence of Htt. Overall, this and our previous studies lend strong support to two important premises: (1) HD pathogenesis has an important developmental component and (2) loss-of-function mechanisms operate at the core of this pathogenic component. These premises have major implications for the modeling of HD because they support the use of loss-of$\mathrm{Htt}$ function models that are impervious to the confounding effects of disease models carrying extremely long and less physiologically relevant polyglutamine tracts to induce pathology.

Each conditional knock-out model exhibited unique profiles of basal ganglia degeneration (severe in the caudal region of the $\mathrm{Htt}^{\mathrm{flx}}$;Gsx2-Cre striatum; mild but global within the striatum and severe in the GP of $\mathrm{Htt}^{\mathrm{flx}} ; \mathrm{Nkx} 2.1-\mathrm{Cre}$ mice). It is noteworthy that these profiles of cell loss complement each other in fully reproducing the caudorostral/mediolateral profile of basal ganglia degeneration observed in HD patients (Vonsattel et al., 1985, 2008; Kassubek et al., 2004). In contrast to the findings in the striatum, no cortical cell loss was detectable in any of our Htt null subpallial models. These findings are in agreement with those described by other group that also reported the absence of cortical neuronal loss in a pallial-specific Htt null model (Dragatsis et al., 2018). However, we previously demonstrated the occurrence of neuronal loss within cortical layer VI in a model with pan-neural loss-of-Htt function during development (Arteaga-Bracho et al., 2016). Together, these findings suggest that Htt dependent cortical pathology requires additional mechanisms operating in both pallial and subpallial regions, including the involvement of additional regional neural lineages.

Among other things, the neurogenic potential of the Gsx 2 and Nkx2.1 germinative regions differ from each other in that the former gives rise exclusively to MSNs, whereas the latter gives rise to $\mathrm{PV}$ and cholinergic interneurons. Conversely, these regions have in common the fact that both give rise to GABAergic interneurons, including some of similar neurochemical types, such as $\mathrm{SST}^{+}$interneurons. It is conceivable that these cells play a 


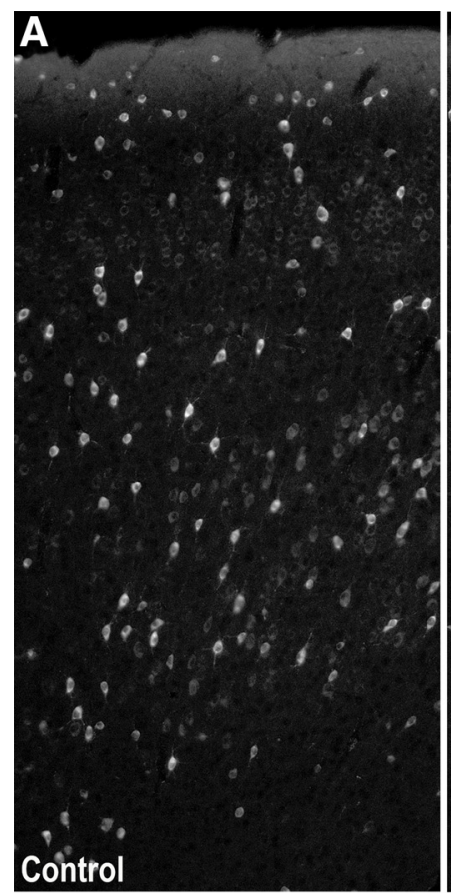

\section{D}

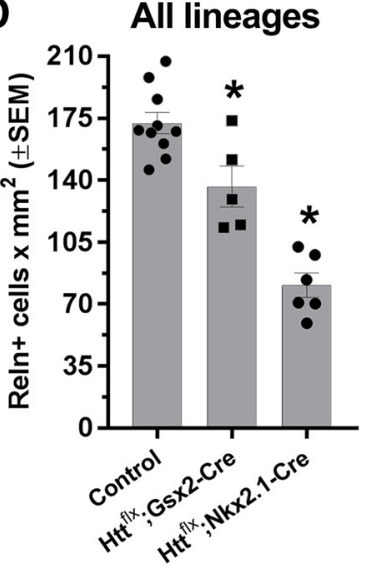

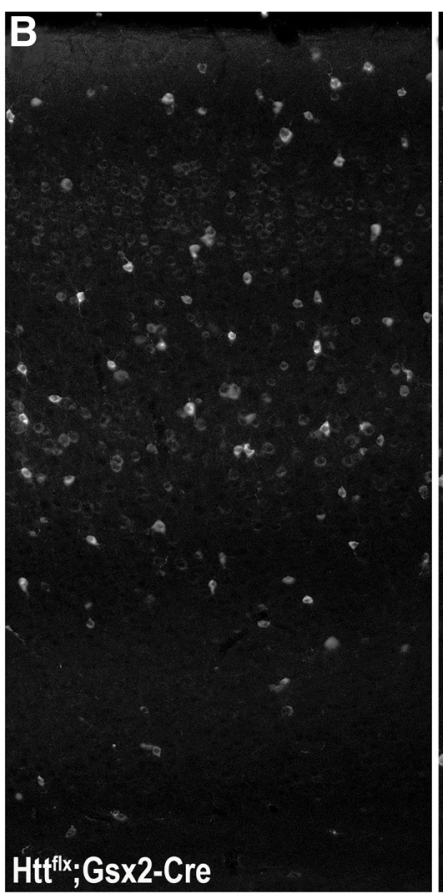

E

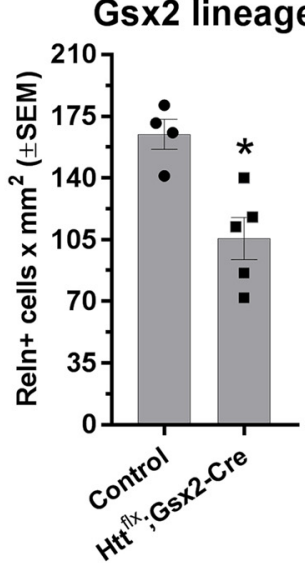

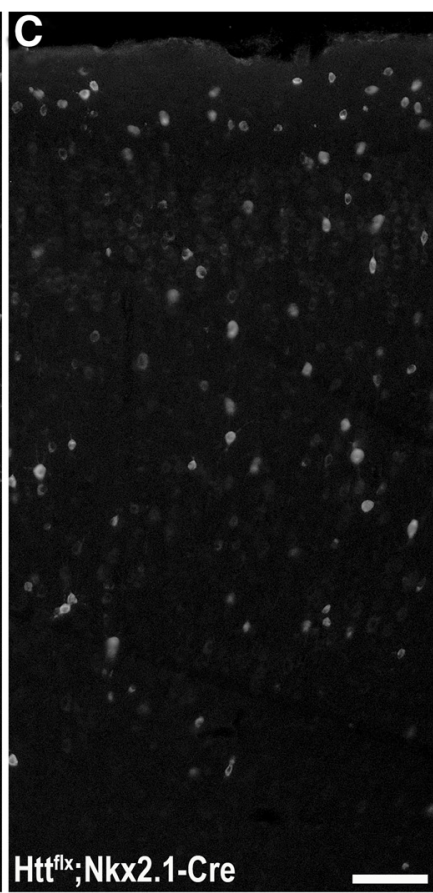

F

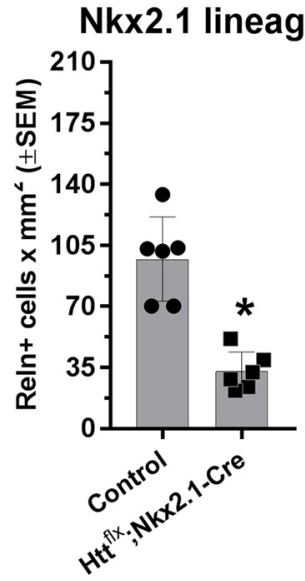

Figure 11. Motor cortex of 1-month-old Htt ${ }^{\mathrm{flx}}$;Gsx2-Cre and $\mathrm{Htt}^{\mathrm{flx}}$; NNkx2.1-Cre mice exhibit a significant reduction in the number of Reln ${ }^{+}$cells. $\boldsymbol{A}-\boldsymbol{C}$, Coronal sections of the motor cortex immunostained against Reln. D, Graph comparing the total number of cortical Reln ${ }^{+}$cells. $\boldsymbol{E}, \boldsymbol{F}$, Graphs comparing the number of cortical Reln ${ }^{+}$cells among Gsx2-derived (E) and Nkx2.1-derived $(\boldsymbol{F})$ derived cells mapped with the ZsGreen reporter. Each dot in the graphs in $\boldsymbol{D}-\boldsymbol{F}$ corresponds to individual biological replicates. ${ }^{*} p<0.005$. Scale bar in $\boldsymbol{C}$ corresponds to $100 \mu \mathrm{m}$.

mechanistic role in eliciting a common core of HD-like abnormalities in $\mathrm{Htt}^{\mathrm{flx}}$; $\mathrm{Gsx} 2-\mathrm{Cre}$ and $\mathrm{Htt}^{\mathrm{flx}}$; $\mathrm{Nkx} 2.1-\mathrm{Cre}$ mice. Indeed, the more severe hyperkinetic and anxiety phenotype, as well as the greater anatomical spread of basal ganglia pathology observed in the $\mathrm{Htt}^{\mathrm{flx}}$; $\mathrm{Nkx} 2$.1-Cre compared with the $\mathrm{Htt}^{\mathrm{fl}}$; $\mathrm{Gsx} 2$-Cre model may be explained by the fact that a larger fraction of forebrain interneuron subtypes are derived from the former rather than from the later subpallial region, further emphasizing the role of interneuron alterations in HD pathogenesis. Consistent with these observations, studies have shown that neuropsychiatric symptomatology strongly correlates with cortical interneuron changes in human HD cases (Ferrante et al., 1986; Kim et al., 2014; Mehrabi et al., 2016). The selective expression of mutant Htt in PV-expressing neurons elicits hyperkinetic behaviors in mice (Dougherty et al., 2014). Consistently, there are interneuron abnormalities in $\mathrm{HD}$, including progressive loss of striatal $\mathrm{PV}^{+}$neurons in HD patients (Reiner et al., 2013; Kim et al., 2014) and alterations in PV interneuron firing responses (Giampà et al., 2009; Cepeda et al., 2013; Paldino et al., 2017). Importantly, de- spite the knock-down of mutant Htt at postnatal day 21, we still detected alterations in GABAergic interneuron spiking activity at 3 months of age in the BACHD model, indicating that these functional abnormalities have a developmental origin (Molero et al., 2016). In addition, multiple studies have described morphological and/or functional alterations in cholinergic and somatostatinergic interneurons in HD (Dawbarn et al., 1985; Ferrante et al., 1985; Albin et al., 1990; Smith et al., 2006; Cepeda et al., 2013; Deng and Reiner, 2016; Reiner and Deng, 2018). Although the existing literature has not revealed numerical differences among cholinergic or somatostatinergic interneurons in HD, no prior study has examined these cells at incipient developmental stages, so any potential interneuron abnormalities in this regard may have been overlooked.

Numerous studies have provided tantalizing evidence of circuit dysmorphogenesis in HD, including: (1) reports of delays in the attainment of compartmental maturation of the striatal chemo-architecture in HD (Molero et al., 2009); (2) data documenting early dendritic spine deficits in HD (Spires et al., 2004; 
Lerner et al., 2012; Murmu et al., 2013); (3) evidence showing abnormalities in corticostriatal and thalamostriatal synaptogenesis in the developing striatum (McKinstry et al., 2014; Buren et al., 2016); and (4) reports showing early alterations of afferent and efferent striatal circuits, including impairments in the balance between excitatory and inhibitory inputs to the direct and indirect MSN pathways (Cummings et al., 2009; André et al., 2011a,b; Galvan et al., 2012; Cepeda et al., 2013; Reiner and Deng, 2018). Interneurons, through multiple mechanisms (e.g., tonic currents of GABA and Reln secretion), regulate key milestones required for neural circuit formation, including neuronal migration and integration, as well as synaptogenesis and axonogenesis (Niu et al., 2008; Wang and Kriegstein, 2008; Sernagor et al., 2010; Fu et al., 2012; Lakatosova and Ostatnikova, 2012; Cellot and Cherubini, 2013; Gaiarsa and Porcher, 2013; Kilb et al., 2013; Luhmann et al., 2015; Oh et al., 2016; Wasser and Herz, 2017). Recent studies have shown that early-born $\mathrm{SST}^{+}$interneurons play a fundamental role in the developmental assembly of the cortical deep layers, acting as transient intermediate relays between the thalamus and both PV interneurons and pyramidal neurons (Tuncdemir et al., 2016). Therefore, it is highly likely that early SST ${ }^{+}$cell deficits in $\mathrm{Htt}^{\mathrm{fl}}$; $\mathrm{Gsx} 2$-Cre and $\mathrm{Htt}^{\mathrm{fl}}$; $\mathrm{Nkx} 2.1$ Cre mice, and presumably in $\mathrm{HD}$, are hampering the maturation of developing forebrain neural circuits. Such maturational deficits have major implications for the subsequent establishment of the activity balance of the striatal direct/indirect pathways, the formation of postnatal excitatory innervation of the striatum, and henceforth the susceptibility to excitotoxicity in adult life (Kozorovitskiy et al., 2012; Peixoto et al., 2016).

In view of our findings, we postulate that the insufficient trophic support associated with early interneuron deficits results in neural circuitries that are inadequate to sustain normal neuronal activity without incurring inordinate degrees of cellular stress (Liu et al., 2001; Qiu et al., 2006; Bouamrane et al., 2016). Indeed, many of the abnormalities occurring long before the onset of HD neurological hallmarks are likely manifestations of the inadequacy of these neural circuits. In addition, such a trophic shortfall may directly or indirectly injure developing cells, impairing their homeostatic responses to stress and therefore their later survival in response to a spectrum of ongoing insults. Moreover, latently damaged or "metastable" neuronal species may be poorly suited to endure both life's ordinary stressors (aging, physiological, and environmental) and the negative effects associated with the ongoing expression of mutant Htt throughout life. Therefore, brain regions displaying the earliest and greatest vulnerabilities to cell death in HD are likely the consequence of synergy between selective developmental insults within discrete brain regions (first hit) and additional postdevelopmental insults (second hit). Overall, our findings add to an emerging number of studies also implicating regional- and neuronal-specific maturational deficits in the pathogenesis of adult-onset neurological disorders, including dystonia, spinocerebellar ataxia type 1 , and Alzheimer's disease (Pappas et al., 2015; Arendt et al., 2017; Edamakanti et al., 2018).

In summary, we have shown that loss-of-Htt function in restricted subpallial lineages, most likely in interneuron subtypes as well as GP GABAergic neurons, robustly generates a composite neurological phenotype reminiscent of HD. These findings have important implications for our understanding of HD pathogenesis, particularly for the elucidation of the mechanistic underpinning of its developmental components. Further confirmation of the role of early interneuron alterations in HD will certainly unveil a novel window for therapeutic intervention and unique mo- lecular targets that have the greatest potential to forestall or prevent disease progression or onset.

\section{References}

Abdi A, Mallet N, Mohamed FY, Sharott A, Dodson PD, Nakamura KC, Suri S, Avery SV, Larvin JT, Garas FN, Garas SN, Vinciati F, Morin S, Bezard E, Baufreton J, Magill PJ (2015) Prototypic and arkypallidal neurons in the dopamine-intact external globus pallidus. J Neurosci 35:6667-6688.

Ahveninen LM, Stout JC, Georgiou-Karistianis N, Lorenzetti V, GlikmannJohnston Y (2018) Reduced amygdala volumes are related to motor and cognitive signs in Huntington's disease: the IMAGE-HD study. Neuroimage Clin 18:881-887.

Albin RL, Reiner A, Anderson KD, Penney JB, Young AB (1990) Striatal and nigral neuron subpopulations in rigid Huntington's disease: implications for the functional anatomy of chorea and rigidity-akinesia. Ann Neurol 27:357-365.

André VM, Fisher YE, Levine MS (2011a) Altered balance of activity in the striatal direct and indirect pathways in mouse models of Huntington's disease. Front Syst Neurosci 5:46.

André VM, Cepeda C, Fisher YE, Huynh M, Bardakjian N, Singh S, Yang XW, Levine MS (2011b) Differential electrophysiological changes in striatal output neurons in Huntington's disease. J Neurosci 31:1170-1182.

Arendt T, Stieler J, Ueberham U (2017) Is sporadic Alzheimer's disease a developmental disorder? J Neurochem 143:396-408.

Arteaga-Bracho EE, Gulinello M, Winchester ML, Pichamoorthy N, Petronglo JR, Zambrano AD, Inocencio J, De Jesus CD, Louie JO, Gokhan S, Mehler MF, Molero AE (2016) Postnatal and adult consequences of loss of huntingtin during development: implications for Huntington's disease. Neurobiol Dis 96:144-155.

Beglinger LJ, Nopoulos PC, Jorge RE, Langbehn DR, Mikos AE, Moser DJ, Duff K, Robinson RG, Paulsen JS (2005) White matter volume and cognitive dysfunction in early Huntington's disease. Cognitive and Behavioral Neurology 18:102-107.

Bohanna I, Georgiou-Karistianis N, Sritharan A, Asadi H, Johnston L, Churchyard A, Egan G (2011) Diffusion tensor imaging in Huntington's disease reveals distinct patterns of white matter degeneration associated with motor and cognitive deficits. Brain Imaging Behav 5:171-180.

Bouamrane L, Scheyer AF, Lassalle O, Iafrati J, Thomazeau A, Chavis P (2016) Reelin-haploinsufficiency disrupts the developmental trajectory of the E/I balance in the prefrontal cortex. Front Cell Neurosci 10:308.

Buren C, Parsons MP, Smith-Dijak A, Raymond LA (2016) Impaired development of cortico-striatal synaptic connectivity in a cell culture model of Huntington's disease. Neurobiol Dis 87:80-90.

Cattaneo E, Zuccato C, Tartari M (2005) Normal huntingtin function: an alternative approach to Huntington's disease. Nat Rev Neurosci 6:919930.

Cellot G, Cherubini E (2013) Functional role of ambient GABA in refining neuronal circuits early in postnatal development. Front Neural Circuits 7:136.

Cepeda C, Galvan L, Holley SM, Rao SP, André VM, Botelho EP, Chen JY, Watson JB, Deisseroth K, Levine MS (2013) Multiple sources of striatal inhibition are differentially affected in Huntington's disease mouse models. J Neurosci 33:7393-7406.

Cepeda-Prado E, Popp S, Khan U, Stefanov D, Rodríguez J, Menalled LB, Dow-Edwards D, Small SA, Moreno H (2012) R6/2 Huntington's disease mice develop early and progressive abnormal brain metabolism and seizures. J Neurosci 32:6456-6467.

Cloud LJ, Rosenblatt A, Margolis RL, Ross CA, Pillai JA, Corey-Bloom J, Tully HM, Bird T, Panegyres PK, Nichter CA, Higgins DS Jr, Helmers SL, Factor SA, Jones R, Testa CM (2012) Seizures in juvenile Huntington's disease: frequency and characterization in a multicenter cohort. Mov Disord 27: 1797-1800.

Conforti P, Besusso D, Bocchi VD, Faedo A, Cesana E, Rossetti G, Ranzani V, Svendsen CN, Thompson LM, Toselli M, Biella G, Pagani M, Cattaneo E (2018) Faulty neuronal determination and cell polarization are reverted by modulating HD early phenotypes. Proc Natl Acad Sci U S A 115:E762E771.

Cummings DM, André VM, Uzgil BO, Gee SM, Fisher YE, Cepeda C, Levine MS (2009) Alterations in cortical excitation and inhibition in genetic mouse models of Huntington's disease. J Neurosci 29:10371-10386.

Dale M, van Duijn E (2015) Anxiety in Huntington's disease. J Neuropsychiatry Clin Neurosci 27:262-271. 
Dawbarn D, De Quidt ME, Emson PC (1985) Survival of basal ganglia neuropeptide Y-somatostatin neurones in Huntington's disease. Brain Res 340:251-260.

Deng YP, Reiner A (2016) Cholinergic interneurons in the Q140 knockin mouse model of Huntington's disease: reductions in dendritic branching and thalamostriatal input. J Comp Neurol 524:3518-3529.

Dodson PD, Larvin JT, Duffell JM, Garas FN, Doig NM, Kessaris N, Duguid IC, Bogacz R, Butt SJ, Magill PJ (2015) Distinct developmental origins manifest in the specialized encoding of movement by adult neurons of the external globus pallidus. Neuron 86:501-513.

Dougherty SE, Hollimon JJ, McMeekin LJ, Bohannon AS, West AB, Lesort M, Hablitz JJ, Cowell RM (2014) Hyperactivity and cortical disinhibition in mice with restricted expression of mutant huntingtin to parvalbuminpositive cells. Neurobiol Dis 62:160-171.

Dragatsis I, Dietrich P, Ren H, Deng YP, Del Mar N, Wang HB, Johnson IM, Jones KR, Reiner A (2018) Effect of early embryonic deletion of huntingtin from pyramidal neurons on the development and long-term survival of neurons in cerebral cortex and striatum. Neurobiol Dis 111:102-117.

Edamakanti CR, Do J, Didonna A, Martina M, Opal P (2018) Mutant ataxin1 disrupts cerebellar development in spinocerebellar ataxia type 1. J Clin Invest 128:2252-2265.

Faul F, Erdfelder E, Buchner A, Lang AG (2009) Statistical power analyses using $G^{\star}$ Power 3.1: tests for correlation and regression analyses. Behav Res Methods 41:1149-1160.

Feigin A, Ghilardi MF, Huang C, Ma Y, Carbon M, Guttman M, Paulsen JS, Ghez CP, Eidelberg D (2006) Preclinical Huntington's disease: compensatory brain responses during learning. Ann Neurol 59:53-59.

Ferrante RJ (2009) Mouse models of Huntington's disease and methodological considerations for therapeutic trials. Biochim Biophys Acta 1792: 506-520.

Ferrante RJ, Kowall NW, Beal MF, Richardson EP Jr, Bird ED, Martin JB (1985) Selective sparing of a class of striatal neurons in Huntington's disease. Science 230:561-563.

Ferrante RJ, Kowall NW, Richardson EP Jr, Bird ED, Martin JB (1986) Topography of enkephalin, substance $P$ and acetylcholinesterase staining in Huntington's disease striatum. Neurosci Lett 71:283-288.

File SE, Mahal A, Mangiarini L, Bates GP (1998) Striking changes in anxiety in Huntington's disease transgenic mice. Brain Res 805:234-240.

Fogarty M, Grist M, Gelman D, Marín O, Pachnis V, Kessaris N (2007) Spatial genetic patterning of the embryonic neuroepithelium generates GABAergic interneuron diversity in the adult cortex. J Neurosci 27: 10935-10946.

Frankin KBJ, Paxinos G (2008) The mouse brain in stereotaxic coordinates. New York: Elsevier.

Fu Y, Wu X, Lu J, Huang ZJ (2012) Presynaptic GABA(B) receptor regulates activity-dependent maturation and patterning of inhibitory synapses through dynamic allocation of synaptic vesicles. Front Cell Neurosci 6:57.

Gaiarsa JL, Porcher C (2013) Emerging neurotrophic role of GABAB receptors in neuronal circuit development. Front Cell Neurosci 7:206.

Galvan L, André VM, Wang EA, Cepeda C, Levine MS (2012) Functional differences between direct and indirect striatal output pathways in Huntington's disease. J Huntingtons Dis 1:17-25.

Giampà C, Middei S, Patassini S, Borreca A, Marullo F, Laurenti D, Bernardi G, Ammassari-Teule M, Fusco FR (2009) Phosphodiesterase type IV inhibition prevents sequestration of CREB binding protein, protects striatal parvalbumin interneurons and rescues motor deficits in the R6/2 mouse model of Huntington's disease. Eur J Neurosci 29:902-910.

Gómez-Tortosa E, MacDonald ME, Friend JC, Taylor SA, Weiler LJ, Cupples LA, Srinidhi J, Gusella JF, Bird ED, Vonsattel JP, Myers RH (2001) Quantitative neuropathological changes in presymptomatic Huntington's disease. Ann Neurol 49:29-34.

HD iPSC Consortium (2017) Developmental alterations in Huntington's disease neural cells and pharmacological rescue in cells and mice. Nat Neurosci 20:648-660.

Hickey MA, Kosmalska A, Enayati J, Cohen R, Zeitlin S, Levine MS, Chesselet MF (2008) Extensive early motor and non-motor behavioral deficits are followed by striatal neuronal loss in knock-in Huntington's disease mice. Neuroscience 157:280-295.

Holtbernd F, Tang CC, Feigin A, Dhawan V, Ghilardi MF, Paulsen JS, Guttman M, Eidelberg D (2016) Longitudinal changes in the motor learning-related brain activation response in presymptomatic Huntington's disease. PLoS One 11:e0154742.

Honrath P, Dogan I, Wudarczyk O, Görlich KS, Votinov M, Werner CJ, Schumann B, Overbeck RT, Schulz JB, Landwehrmeyer BG, Gur RE, Habel U, Reetz K; Enroll-HD investigators (2018) Risk factors of suicidal ideation in Huntington's disease: literature review and data from enroll-HD. J Neurol 265:2548-2561.

Hult Lundh S, Nilsson N, Soylu R, Kirik D, Petersén Å (2013) Hypothalamic expression of mutant huntingtin contributes to the development of depressive-like behavior in the BAC transgenic mouse model of Huntington's disease. Hum Mol Genet 22:3485-3497.

Kassubek J, Juengling FD, Kioschies T, Henkel K, Karitzky J, Kramer B, Ecker D, Andrich J, Saft C, Kraus P, Aschoff AJ, Ludolph AC, Landwehrmeyer GB (2004) Topography of cerebral atrophy in early Huntington's disease: a voxel based morphometric MRI study. J Neurol Neurosurg Psychiatry 75:213-220.

Kerschbamer E, Biagioli M (2015) Huntington's disease as neurodevelopmental disorder: altered chromatin regulation, coding, and non-coding RNA transcription. Front Neurosci 9:509.

Kessaris N, Fogarty M, Iannarelli P, Grist M, Wegner M, Richardson WD (2006) Competing waves of oligodendrocytes in the forebrain and postnatal elimination of an embryonic lineage. Nat Neurosci 9:173-179.

Kilb W, Kirischuk S, Luhmann HJ (2013) Role of tonic GABAergic currents during pre- and early postnatal rodent development. Front Neural Circuits 7:139.

Kim EH, Thu DC, Tippett LJ, Oorschot DE, Hogg VM, Roxburgh R, Synek BJ, Waldvogel HJ, Faull RL (2014) Cortical interneuron loss and symptom heterogeneity in huntington disease. Ann Neurol 75:717-727.

Köhler C (2016) Granulovacuolar degeneration: a neurodegenerative change that accompanies tau pathology. Acta Neuropathol 132:339-359.

Kozorovitskiy Y, Saunders A, Johnson CA, Lowell BB, Sabatini BL (2012) Recurrent network activity drives striatal synaptogenesis. Nature 485: $646-650$.

Lakatosova S, Ostatnikova D (2012) Reelin and its complex involvement in brain development and function. Int J Biochem Cell Biol 44:1501-1504.

Lerner RP, Trejo Martinez Ldel C, Zhu C, Chesselet MF, Hickey MA (2012) Striatal atrophy and dendritic alterations in a knock-in mouse model of Huntington's disease. Brain Res Bull 87:571-578.

Liu WS, Pesold C, Rodriguez MA, Carboni G, Auta J, Lacor P, Larson J, Condie BG, Guidotti A, Costa E (2001) Down-regulation of dendritic spine and glutamic acid decarboxylase 67 expressions in the reelin haploinsufficient heterozygous reeler mouse. Proc Natl Acad Sci U S A 98: 3477-3482.

Luhmann HJ, Fukuda A, Kilb W (2015) Control of cortical neuronal migration by glutamate and GABA. Front Cell Neurosci 9:4.

Mallet N, Micklem BR, Henny P, Brown MT, Williams C, Bolam JP, Nakamura KC, Magill PJ (2012) Dichotomous organization of the external globus pallidus. Neuron 74:1075-1086.

Marques Sousa C, Humbert S (2013) Huntingtin: here, there, everywhere! J Huntingtons Dis 2:395-403.

Martinez-Horta S, Perez-Perez J, van Duijn E, Fernandez-Bobadilla R, Carceller M, Pagonabarraga J, Pascual-Sedano B, Campolongo A, RuizIdiago J, Sampedro F, Landwehrmeyer GB, Landwehrmeyer GB, Kulisevsky J (2016) Neuropsychiatric symptoms are very common in premanifest and early stage Huntington's disease. Parkinsonism Relat Disord 25:58-64.

McKinstry SU, Karadeniz YB, Worthington AK, Hayrapetyan VY, Ozlu MI, Serafin-Molina K, Risher WC, Ustunkaya T, Dragatsis I, Zeitlin S, Yin $\mathrm{HH}$, Eroglu C (2014) Huntingtin is required for normal excitatory synapse development in cortical and striatal circuits. J Neurosci 34:94559472.

Mehrabi NF, Waldvogel HJ, Tippett LJ, Hogg VM, Synek BJ, Faull RL (2016) Symptom heterogeneity in Huntington's disease correlates with neuronal degeneration in the cerebral cortex. Neurobiol Dis 96:67-74.

Menalled L, El-Khodor BF, Patry M, Suárez-Fariñas M, Orenstein SJ, Zahasky B, Leahy C, Wheeler V, Yang XW, MacDonald M, Morton AJ, Bates G, Leeds J, Park L, Howland D, Signer E, Tobin A, Brunner D (2009) Systematic behavioral evaluation of Huntington's disease transgenic and knock-in mouse models. Neurobiol Dis 35:319-336.

Molero AE, Gokhan S, Gonzalez S, Feig JL, Alexandre LC, Mehler MF (2009) Impairment of developmental stem cell-mediated striatal neurogenesis 
and pluripotency genes in a knock-in model of Huntington's disease. Proc Natl Acad Sci U S A 106:21900-21905.

Molero AE, Arteaga-Bracho EE, Chen CH, Gulinello M, Winchester ML, Pichamoorthy N, Gokhan S, Khodakhah K, Mehler MF (2016) Selective expression of mutant huntingtin during development recapitulates characteristic features of Huntington's disease. Proc Natl Acad Sci U S A 113:5736-5741.

Molina-Calavita M, Barnat M, Elias S, Aparicio E, Piel M, Humbert S (2014) Mutant huntingtin affects cortical progenitor cell division and development of the mouse neocortex. J Neurosci 34:10034-10040.

Murmu RP, Li W, Holtmaat A, Li JY (2013) Dendritic spine instability leads to progressive neocortical spine loss in a mouse model of Huntington's disease. J Neurosci 33:12997-13009.

Nguyen GD, Molero AE, Gokhan S, Mehler MF (2013a) Functions of huntingtin in germ layer specification and organogenesis. PLoS One 8:e72698.

Nguyen GD, Gokhan S, Molero AE, Mehler MF (2013b) Selective roles of normal and mutant huntingtin in neural induction and early neurogenesis. PLoS One 8:e64368.

Niu S, Yabut O, D’Arcangelo G (2008) The reelin signaling pathway promotes dendritic spine development in hippocampal neurons. J Neurosci 28:10339-10348.

Nóbrega-Pereira S, Gelman D, Bartolini G, Pla R, Pierani A, Marín O (2010) Origin and molecular specification of globus pallidus neurons. J Neurosci 30:2824-2834.

Oh WC, Lutzu S, Castillo PE, Kwon HB (2016) De novo synaptogenesis induced by GABA in the developing mouse cortex. Science 353:1037-1040.

Okamoto K, Hirai S, Iizuka T, Yanagisawa T, Watanabe M (1991) Reexamination of granulovacuolar degeneration. Acta Neuropathol 82:340-345.

Orvoen S, Pla P, Gardier AM, Saudou F, David DJ (2012) Huntington's disease knock-in male mice show specific anxiety-like behaviour and altered neuronal maturation. Neurosci Lett 507:127-132.

Paldino E, Cardinale A, D'Angelo V, Sauve I, Giampà C, Fusco FR (2017) Selective sparing of striatal interneurons after poly (ADP-Ribose) polymerase 1 inhibition in the R6/2 mouse model of Huntington's disease. Front Neuroanat 11:61.

Pappas SS, Darr K, Holley SM, Cepeda C, Mabrouk OS, Wong JM, LeWitt TM, Paudel R, Houlden H, Kennedy RT, Levine MS, Dauer WT (2015) Forebrain deletion of the dystonia protein torsinA causes dystonic-like movements and loss of striatal cholinergic neurons. Elife 4:e08352.

Parievsky A, Cepeda C, Levine MS (2012) Evidence from the R6/2 mouse model of Huntington's disease for using abnormal brain metabolism as a biomarker for evaluating therapeutic approaches for treatment. Future Neurol 7:527-530.

Peixoto RT, Wang W, Croney DM, Kozorovitskiy Y, Sabatini BL (2016) Early hyperactivity and precocious maturation of corticostriatal circuits in Shank3B(-/-) mice. Nat Neurosci 19:716-724.

Pesold C, Impagnatiello F, Pisu MG, Uzunov DP, Costa E, Guidotti A, Caruncho HJ (1998) Reelin is preferentially expressed in neurons synthesizing gamma-aminobutyric acid in cortex and hippocampus of adult rats. Proc Natl Acad Sci U S A 95:3221-3226.

Petersén A, Björkqvist M (2006) Hypothalamic-endocrine aspects in Huntington's disease. Eur J Neurosci 24:961-967.

Pfaffl MW, Horgan GW, Dempfle L (2002) Relative expression software tool (REST) for group-wise comparison and statistical analysis of relative expression results in real-time PCR. Nucleic Acids Res 30:e36.

Phillips O, Squitieri F, Sanchez-Castaneda C, Elifani F, Caltagirone C, Sabatini U, Di Paola M (2014) Deep white matter in Huntington's disease. PLoS One 9:e109676.

Qin S, Madhavan M, Waclaw RR, Nakafuku M, Campbell K (2016) Characterization of a new Gsx2-cre line in the developing mouse telencephalon. Genesis 54:542-549.

Qiu S, Korwek KM, Pratt-Davis AR, Peters M, Bergman MY, Weeber EJ (2006) Cognitive disruption and altered hippocampus synaptic function in reelin haploinsufficient mice. Neurobiol Learn Mem 85:228-242.

Reiner A, Deng YP (2018) Disrupted striatal neuron inputs and outputs in Huntington's disease. CNS Neurosci Ther 24:250-280.

Reiner A, Shelby E, Wang H, Demarch Z, Deng Y, Guley NH, Hogg V, Rox- burgh R, Tippett LJ, Waldvogel HJ, Faull RL (2013) Striatal parvalbuminergic neurons are lost in Huntington's disease: implications for dystonia. Mov Disord 28:1691-1699.

Renoir T, Zajac MS, Du X, Pang TY, Leang L, Chevarin C, Lanfumey L, Hannan AJ (2011) Sexually dimorphic serotonergic dysfunction in a mouse model of Huntington's disease and depression. PLoS One 6:e22133.

Rosas HD, Tuch DS, Hevelone ND, Zaleta AK, Vangel M, Hersch SM, Salat DH (2006) Diffusion tensor imaging in presymptomatic and early Huntington's disease: selective white matter pathology and its relationship to clinical measures. Mov Disord 21:1317-1325.

Schneider CA, Rasband WS, Eliceiri KW (2012) NIH image to ImageJ: 25 years of image analysis. Nat Methods 9:671-675.

Sernagor E, Chabrol F, Bony G, Cancedda L (2010) GABAergic control of neurite outgrowth and remodeling during development and adult neurogenesis: general rules and differences in diverse systems. Front Cell Neurosci 4:11

Sharaf A, Rahhal B, Spittau B, Roussa E (2015) Localization of reelin signaling pathway components in murine midbrain and striatum. Cell Tissue Res 359:393-407.

Siebzehnrübl FA, Raber KA, Urbach YK, Schulze-Krebs A, Canneva F, Moceri S, Habermeyer J, Achoui D, Gupta B, Steindler DA, Stephan M, Nguyen HP, Bonin M, Riess O, Bauer A, Aigner L, Couillard-Despres S, Paucar MA, Svenningsson P, Osmand A, et al. (2018) Early postnatal behavioral, cellular, and molecular changes in models of Huntington disease are reversible by HDAC inhibition. Proc Natl Acad Sci U S A 115:E8765E8774.

Simon P, Dupuis R, Costentin J (1994) Thigmotaxis as an index of anxiety in mice. influence of dopaminergic transmissions. Behav Brain Res 61:59-64.

Skarnes WC, Rosen B, West AP, Koutsourakis M, Bushell W, Iyer V, Mujica AO, Thomas M, Harrow J, Cox T, Jackson D, Severin J, Biggs P, Fu J, Nefedov M, de Jong PJ, Stewart AF, Bradley A (2011) A conditional knockout resource for the genome-wide study of mouse gene function. Nature 474:337-342.

Smith R, Chung H, Rundquist S, Maat-Schieman ML, Colgan L, Englund E, Liu YJ, Roos RA, Faull RL, Brundin P, Li JY (2006) Cholinergic neuronal defect without cell loss in Huntington's disease. Hum Mol Genet 15:3119-3131.

Spires TL, Grote HE, Garry S, Cordery PM, Van Dellen A, Blakemore C, Hannan AJ (2004) Dendritic spine pathology and deficits in experiencedependent dendritic plasticity in R6/1 Huntington's disease transgenic mice. Eur J Neurosci 19:2799-2807.

Tuncdemir SN, Wamsley B, Stam FJ, Osakada F, Goulding M, Callaway EM, Rudy B, Fishell G (2016) Early somatostatin interneuron connectivity mediates the maturation of deep layer cortical circuits. Neuron 89:521-535.

van Wamelen DJ, Aziz NA, Roos RA, Swaab DF (2014) Hypothalamic alterations in Huntington's disease patients: comparison with genetic rodent models. J Neuroendocrinol 26:761-775.

Vonsattel JP, Myers RH, Stevens TJ, Ferrante RJ, Bird ED, Richardson EP Jr (1985) Neuropathological classification of Huntington's disease. J Neuropathol Exp Neurol 44:559-577.

Vonsattel JP, Keller C, Del Pilar Amaya M (2008) Neuropathology of Huntington's disease. Handb Clin Neurol 89:599-618.

Wang DD, Kriegstein AR (2008) GABA regulates excitatory synapse formation in the neocortex via NMDA receptor activation. J Neurosci 28:5547-5558.

Wasser CR, Herz J (2017) Reelin: neurodevelopmental architect and homeostatic regulator of excitatory synapses. J Biol Chem 292:1330-1338.

Welagen J, Anderson S (2011) Origins of neocortical interneurons in mice. Dev Neurobiol 71:10-17.

West MJ (1999) Stereological methods for estimating the total number of neurons and synapses: issues of precision and bias. Trends Neurosci 22:51-61.

Xu Q, Tam M, Anderson SA (2008) Fate mapping Nkx2.1-lineage cells in the mouse telencephalon. J Comp Neurol 506:16-29. 